\title{
Polyester Fabric With Fluorescent Properties Using Microwave Technology For Anti-Counterfeiting Applications
}

Fredj Saad ( $\square$ fredj93.saad@gmail.com )

ENIM: Ecole Nationale d'Ingenieurs de Monastir https://orcid.org/0000-0001-6112-2616

\section{Ayda Baffoun}

École Nationale d'Ingénieurs de Monastir: Ecole Nationale d'Ingenieurs de Monastir

\section{Boris Mahltig}

Niederrhein University of Applied Sciences: Hochschule Niederrhein

\section{Mohamed Hamdaoui}

École Nationale d'Ingénieurs de Monastir: Ecole Nationale d'Ingenieurs de Monastir

\section{Research Article}

Keywords: Microwave technique, fluorescein, UV absorber, polyester fabric, fluorescence

Posted Date: August 6th, 2021

DOl: https://doi.org/10.21203/rs.3.rs-721174/v1

License: (c) (i) This work is licensed under a Creative Commons Attribution 4.0 International License.

Read Full License

Version of Record: A version of this preprint was published at Journal of Fluorescence on November 23rd, 2021. See the published version at https://doi.org/10.1007/s10895-021-02845-7. 


\section{Abstract}

The article presented concerns the application of fluorescein as a fluorescent material for anticounterfeiting technology which will allow the labeling and identification of legitimate articles in the textile field. Fluorescein has been applied to polyester fabrics by microwave irradiation technique in the presence of a UV absorber. Thus, its presence in the textile substrate is detectable following an excitation at a specific wavelength belonging to the Ultra-violet zone, which makes this material very effective for tracking and detecting counterfeit articles. Fluorescent samples are characterized morphologically by scanning electron microscopy (SEM) and quantitatively by optical spectroscopy such as reflectance and transmission measurements. The treated samples show under UV light a yellowish green emission with a slight yellow coloration of the polyester fiber. The UV absorber applied to the fluorescent solution improves the light resistance of the treated samples by $25 \%$. Their addition to the bath can also ensure the production of a protective fabric against UV.

\section{Introduction}

Counterfeiting is defined as the activity of making a product that resembles another in order to compete with it or to deceive the consumer. The objective resemblance between the two products requires careful examination, often by experts, to distinguish the original from the fake. Today, counterfeiting affects many fields such as cosmetics, pharmaceutical manufacturing and the falsification of official documents, with sometimes dramatic consequences for the health of consumers. Counterfeiting represents about $7 \%$ of world trade and costs more than 350 billion dollars [1]. The fight against this scourge is made all the more difficult by the fact that globalization has considerably increased the volume of trade and that technological progress has made copies increasingly difficult to detect. In response to this challenge, there is a constant demand for new and better anti-counterfeiting technologies. To overcome this problem, anti-counterfeiting technology is being developed and constantly improved to mark authentic items.

The use of smart fluorescent materials is one of the most preferred approaches to protect documents such as certificates, banknotes, diplomas and packaging [2]. These fluorescent materials, as new functional materials, require good fluorescence properties (high intensity and long emission duration). In general, most of the optical techniques to fight against falsification are based only on the excitation of these materials by UV or Infrared light giving a very specific emission color $[3,4]$.

Noting that there are different security measures to fight against counterfeiting. One example is the use of nanoparticle-based luminescent materials that have been widely used as security inks. Bionanocomposite films composed of CdTe quantum dots (QDs) decorated with cellulose nanofibrils (CNFs) [5], color fluorescent patterns obtained by multicolor polymer dot inks [6], fluorescent inks fluorescently encoded during the lifetime of carbon dot CDs $[7,8]$ and other hybrids [9] have been reported as luminescent nanoparticles. In addition, the incorporation of complex rare earths is proving to be a promising method in the fight against counterfeiting [10-12]. Another approach is to use security fibers 
that can be visible under daylight and/or ultraviolet light and are associated with the structure of the paper during its production. Some of these fibers have the ability to change color under UV light $[13,14]$. Recent work has focused on the development of MOFs (metal-organic frameworks) encapsulated in anticounterfeiting dyes that have a long luminescence lifetime [15].

The textile industry is one of the most affected by counterfeiting. Some research focuses on a specific method of marking and identifying legal items, such as the use of microencapsulation technology. This technique uses microcapsules containing a dye or activator applied directly to the yarn or to a woven label [16]. In addition, the technology of microencapsulating radio frequency identification (RFID) chips in the yarn of textiles and garments has been developed. This chip is integrated from the design of the garment [17]. Other work has focused on the use of fluorescent silica nanoparticles, Cornell dots (C dots) embedded in electrospun cellulose acetate (CA) fibers [2].

More recently, the use of functional fibers such as polypropylene (PP) fluorescent fibers with organicinorganic hybrid rare earth complex materials has emerged as an alternative method to mimicry using a special spinning process $[18,19]$. Due to the low thermal stability and poor mechanical properties of the rare earth complex, the practical application of functional fibers is limited in melt spinning with polymeric materials at high temperatures [20-22].

Inspired by all these previous works, fluorescent optical marking can be a good solution considered to ensure effective textile traceability. Fluorescein tracer, as a small fluorescent emitter, is an excellent choice for many applications. Since the late 1800s, fluorescein has been widely used for groundwater tracing due to its safety, availability and ability to be adsorbed onto activated coconut charcoal. In the medical field, fluorescein and its derivatives are commonly used as anionic fluorophores for healthcare applications (ophthalmology, gastrointestinal endoscopy, neurosurgery, dermatology, etc.). It is also used for the development of biological detection probes [25] due to its high molar absorption capacity and good quantum efficiency in aqueous media $(0.92$ at $\mathrm{pH} 9)$. Due to their attractive properties of high fluorescence quantum efficiency, low toxicity, low cost, and water solubility [26,27], the application of fluorescein in the textile field has given satisfaction to label and identify legitimate items. In this context, our research team performed the application of fluorescein in cotton yarns by a simple anti-counterfeiting marking process in 2019 to provide identification of yarns such as composition labels, embroidered logos, or even seams [28].

The objective of our work is to develop a technology to ensure a better traceability. We will try to obtain a textile fluorescent enough as soon as we excite it under UV while minimizing its surface coloration. So roughly speaking we try to maximize the reflectance of the textile samples and their fluorescence at the same time. For this, a fluorescein dye is applied to a $100 \%$ polyester textile fabric using the microwave irradiation technique. In order to evaluate the surface coloration of the textile in relation to fluorescence, the prepared fluorescent sample is characterized by measuring the reflectance as a function of the absorption and emission wavelength of the dye. In addition, the transmittance of the fluorescent samples 
was measured to evaluate the effect of the UV absorbers on the treated polyester as well as the domestic wash fastness and light fastness.

\section{Material And Methods}

\subsection{Materials}

A polyester fabric with a grammage of $154 \mathrm{~g} / \mathrm{m}^{2}$ was used. The scouring treatment was carried out at $80^{\circ} \mathrm{C}$ for $60 \mathrm{~min}$ in a solution with a liquor/fibre ratio of $40: 1(\mathrm{~mL} / \mathrm{g})$, containing $\mathrm{Na}_{2} \mathrm{CO}_{3}\left(0.5 \mathrm{gL}^{-1}\right)$ and a wetting agent $\left(10 \mathrm{gL}^{-1}\right)$. The samples were then successively rinsed with hot and cold water and dried at $60^{\circ} \mathrm{C}$ for $24 \mathrm{~h}$. The bleaching treatment was carried out at $100^{\circ} \mathrm{C}$ for $60 \mathrm{~min}$ in a solution with the same liquor/fibre ratio, containing sodium chlorite $\left(5 \mathrm{gL}^{-1}\right)$ and sodium nitrate $\left(2 \mathrm{gL}^{-1}\right)$. The $\mathrm{pH}$ was adjusted to 4.5 by the addition of acetic acid. After bleaching, the samples were washed with water and dried at $60^{\circ} \mathrm{C}$ for 24 hours.

The size of the fabric samples for the dyeing process using a microwave system had to be adapted to the volume of the vessel used in the microwave. The used vessels have a maximum capacity of $80 \mathrm{ml}$ of which, however, only a $50 \mathrm{ml}$ volume can be processed by the microwave. As the vessel has a height of 7 $\mathrm{cm}$ the fabric samples should have a defined width of $6 \mathrm{~cm}$.

In this paper, fluoresein was used as a fluorescent organic dye (figure 1). It is a synthetic organic compound available as an orange/dark red powder soluble in water and alcohol. It has an absorption maximum from $460 \mathrm{~nm}$ to $490 \mathrm{~nm}$ and an emission maximum from $520 \mathrm{~nm}$ to $550 \mathrm{~nm}$ (in water). This shift in absorption and emission wavelength can be explained by the sensitivity of the fluorescent molecule to the $\mathrm{pH}$ of the bath [29]. This tracer has a greenish yellow emission in water under UV excitation. It is rare in nature to find such coloring which has the ability to contrast with most backgrounds. In addition, the human eye recognizes green-yellow better than any other color under various light conditions, making detection of counterfeit items unique and easy.

Fluorescein and many of its derivatives exhibit multiple, $\mathrm{pH}$-dependent ionic equilibria. Both the phenol and carboxylic acid functional groups of fluorescein are almost totally ionized in aqueous solutions above pH 9 (Figure 1). Acidification of the fluorescein dianion first protonates the phenol (pKa 6.4) to yield the fluorescein monoanionic, then the carboxylic acid (pKa 2.1).

In this document, four concentrations of fluorescein $0.1 \%, 0.2 \%, 0.3 \%$ and $0.4 \%$ were used in order to have a fluorescent material excited under the UV lamp and maintain its white colour under daylight. The dyeing was carried out in the presence of the XHT-S dispersant from CHT (CHT, Tübingen, Germany) as the dispersing agent. In order to maintain a constant $\mathrm{pH}$ of the dye bath in a weakly acidic region and also to avoid agglomeration of the dye particles, Meropan CIT (CHT, Tübingen, Germany) was added to the dye bath to obtain a pH of approximately 4 to 4.5. The UV absorber Tanuval UVL (TANATEX Chemicals B.V., BA Ede Netherlands) $\mathrm{pH} 3-5$, was used for the dispersion dyeing of polyester. It has an anionic character 
and contains a dispersing agent. It provided a high UV protection function and further improved the light fastness of the dye application on polyester materials.

After the dyeing process a reductive cleaning process is performed. The used reductive cleaning agent is Cyclanon ${ }^{\circledR}$ Clear ARC from BASF. It is purchased in powder form and is chemically composed of reducing agent, alkali and dispersing agent. Cyclanon Clear ARC is used to remove the disperse dye from the fibre surface which is not fixed, as well as for the improvement of fastness properties of dyed polyester or polyester blends. Cyclanon Clear ARC has a pH-value of $11(10 \%)$ and is therefore alkaline.

After the preparation of the fabric samples the dye bath for each single sample is prepared. The dye bath contains all products necessary for the dyeing process, such as the dye itself, chemicals and dyeing auxiliaries. To prevent measuring inaccuracies due to the small amounts needed and to keep set tolerances stock solutions, containing either the additives or the dye are prepared. The stock solution factor is multiplied with the calculated amount of dyestuff to determine the amount of dye stock solution, which needs to be weighed up for the preparation of the dye bath.

The application of the fluorescent dye to the polyester fabric was developed using microwave irradiation technology.

\subsection{Methods}

\subsubsection{Microwave irradiation technique}

In textile processing it is necessary to apply heat as in dye fixation, heat setting or drying the product. Heat can be transferred to the material by radiation, conduction and convection. These three ways of transferring can be used either separately or in combination. The saving of time and energy is of immediate interest to the textile industry. The introduction of new techniques which will allow less energy to be used: is a highly important area of activity to consider. The textile industry has investigated many uses for microwave energy such as heating, drying, dye fixation, printing and curing of resin finished fabrics.

Microwave heating is defined as dielectric heating. Dielectric microwave heating depends on the ability of a specific material (e.g., a solvent or reagent) to absorb microwave energy and convert it into heat. Such materials are called dielectric materials, characterized by a dipole moment. This heating involves the agitation of polar molecules or ions that oscillate under the effect of an oscillating electric or magnetic field.

The energy of microwave photons is quite low compared with the chemical bond energies and, thus, microwaves do not directly affect the molecular structure of a compound and they do not change the electronic configuration of atoms [30]. During the microwave heating process, the microwaves passes easily through the vessel which is transparent to the microwave energy. Therefore, the sample-solvent 
mixture inside the reaction vessel is directly heated, without a heating of the reaction vessel itself. Furthermore, this enables a simultaneously heating of all

particles inside the sample and consequently an even temperature of the heated sample material. Whereas, conventional heating first heats up the reaction metal vessel which then transfers the heat to the sample-solvent mixture. The vessel is heated up by conductive heating, realised using an external heat source such as an oil-bath or heating mantle. The heating of the reaction sample leads to an uneven temperature of the sample as the hot vessel heats first the vessel content which is in contact to the metal vessel. The heating of the vessel itself is resulting in so-called wall effects, defined as the hot vessel surface. Those wall effects can be avoided in the microwave heating process, as the heat is directly generated inside the reaction mixture [31-32]. This process is much more efficient and less time consuming than conventional heating.

The process duration can be reduced from hours to minutes or even seconds which avoid side reactions and therefore the formation of by-products. The higher efficiency leads to a reduced energy consumption and thus reduced cost.

The dyeing process using a microwave-assisted system is performed using a Focused Microwave Synthesis System, Model Discover from manufacturer CEM Corporation, shown in figure 2. The focused microwave system enables chemical reactions inside a reaction vessel by the direct application of microwave energy to the vessel content. The reactions are performed with closed vessel conditions (autoclave). This enables reactions to be run at high temperature, even far above the boiling point of the used solvents, and high pressure.

Using the Focused Microwave Synthesis System, the operator can choose from four different method control options to regulate the way microwave energy is applied. These options are: Standard Control, Power-Time Control, SPS Coupling, and SPS Deprotection. SPS deprotection. For the applications presented in this work, the standard control is applied.

The standard control option gives the user the ability to individually set the following process parameters: microwave power, temperature, pressure, run time (the maximum run time of the method for situations where the control point is not reached), hold time (the time during which the system maintains the control parameters), stirring and cooling of the dye bath. The process parameters used have been described in Table 1.

Table 1: Process parameters for the microwave dyeing application 


\begin{tabular}{ll} 
Parameters & Values \\
\hline Microwave power & 250 watts \\
\hline Temperature control point & $80^{\circ} \mathrm{C}, 100^{\circ} \mathrm{C}, 130^{\circ} \mathrm{C}$ and $140^{\circ} \mathrm{C}$ \\
\hline Run time & 10 minutes \\
\hline Hold time & $5 \mathrm{~min}, 10$ min and $15 \mathrm{~min}$
\end{tabular}

\subsubsection{Spectral Measurement Procedure}

The reflectance and fluorescence measurements were given by the Datacolor 400TM spectrophotometer in the visible part of the spectrum $(400-700 \mathrm{~nm})$. All measurements were performed under the conditions of a D65 illuminant and $10^{\circ}$ observer.

Once the textile sample is excited by daylight, the spectrophotometer shows a reflectance curve as a function of the wavelength having the following look (Figure 1). The standard polyester (white) has a reflectance value of $80 \%$. The curve of fluorescent polyester gives us two local extremum; a minimum at $460 \mathrm{~nm}$ equivalent to the absorption wavelength of fluorescein in which the reflectance of fluorescent samples can be measured and a maximum at $550 \mathrm{~nm}$ corresponds to the emission wavelength of the fluorescent molecule. This last peak tells us about the fluorescence quality of treated textiles. Indeed, the emitted fluorescent light is added to the light reflected by the treated material, by that producing an apparent increase of reflectance in the green region [33]. Thus, any value of the reflectance of the fluorescent polyester greater than $80 \%$ at $550 \mathrm{~nm}$ can give us an approximation of the quality of the fluorescence and allows us to make a comparative study between the treated samples.

The values of the transmission curves were illustrated in the visible part of the UV spectrum $(220-450 \mathrm{~nm})$ using the transmission spectrophotometer UV-2600 from Shimadzu. These spectroscopic measurements were carried out in an arrangement of diffuse reflection and diffusive transmission using an integration sphere. So, for the measurement of the transmission of a textile sample the sample is placed in the same window of the integrated sphere as the measurement light beam is entering the integrated sphere. Thus, the light beam is directly passed onto the textile sample. Consequently, the light transmitted by the sample enters the sphere and is detected.

\subsubsection{Evaluation of colorfastness}

Different color fastness properties of the dyed samples were evaluated according to the following methods: color fastness to washing (ISO 105 C06) and color fastness to light (ISO B02-014). The washing fastness tests are carried out in accordance with the method described in ISO 105-C06, B1S test conditions; $50^{\circ} \mathrm{C}$ temperature, $30 \mathrm{~min}$ and 10 steel balls.

For the light fastness standard, the first method was followed by determining the fluorescence time of the treated samples as well as the shade evaluation obtained with the blue scale. In fact, to ensure the 
traceability and detection of counterfeit articles, polyester treated with fluorescein can only be detected after excitation under UV light [34]. Therefore, it is very important to determine the fluorescence duration of the textile support alongside its assessment with the blue scale. This duration is defined by the start of exposure of the articles to UV until the total disappearance of their fluorescence.

\subsubsection{Scanning Electron Microscopy}

The microscopic investigations (SEM scanning electron microscopy) of the treated tissues were carried out using a microanalyzer with scanning electron probe (type JSM-IT 100) -Japan. The micrographs were taken at four magnifications, namely $50,500,1000$ and 2000 using an acceleration voltage of $15 \mathrm{kV}$.

\section{Results And Discussion}

Despite containing planar aromatic ring systems, highly fluorescent dye molecules often contain also structural characteristics that confer a considerable degree of non-planarity. Planar molecules have a tendency to aggregate, in extreme cases becoming pigmentary, and dissipate excited state energy through relaxation processes which involve intermolecular interactions. The classical example of a fluorescent dye, fluorescein, provides an example of a rigid yet non-planar molecular structure which leads to high fluorescence intensity [35].

This fluorescent dye is acidic in nature due to the presence of $\mathrm{COOH}$ acid groups in its conjugated structure. At an acid-neutral $\mathrm{pH}$, fluorescein has no charged group, which limits its solubility in water. In order to improve this solubility and to obtain a good dispersion into the bath, a dispersing agent is added. Therefore its application on polyester will take place thanks to its dispersed character. Dispersed dyes were applied to polyester without and with the inclusion of a carrier in the dye bath. The use of these carriers has caused many problems for the dyer, including the residual odor of the carrier on fabrics and the reduction in lightfastness of dyed fabrics due to the residual carrier [29]. Therefore, the process was carried out without the addition of catalyst.

The effect of temperature on the reflectance of fluorescent sample is studied at first. The curve allows a minimum at point $460 \mathrm{~nm}$ and a maximum at point $560 \mathrm{~nm}$ corresponds respectively to the absorption and emission wavelength of the dye molecule.

\subsection{Effect of temperature on the reflectance}

The dyeing temperature is an important factor, it plays a crucial role in the coloration of thermoplastic fibers, especially for hydrophobic polyester according to traditional dyeing theory.

According to the curves above (Figure 4), it is clear that the reflectance increases proportionally with temperature. In fact, heating the dye liquor accelerates the strike rate and the diffusion of the dyes inside the fiber structure. Within the fiber polymer, the dye molecules are held by van der Waals forces. The use 
of maximum process temperature of $140^{\circ} \mathrm{C}$ leads to a rather small reflectance value which is very far from the reflectance of standard polyester (white).

Figure 3 describes the variation of the reflectance as a function of wavelength by varying the process temperature $80^{\circ} \mathrm{C}, 100^{\circ} \mathrm{C}, 130^{\circ} \mathrm{C}$ and $140^{\circ} \mathrm{C}$ for each concentration of the fluorescent marker while the process duration is set to $5 \mathrm{~min}$.

According to this figure, the four curves obtained have the same tendency. For a concentration of $0.1 \%$, $0.2 \%$ and $0.3 \%$ the reflectance increases until reaching a threshold at $100^{\circ} \mathrm{C}$ whereas for the concentration of $0.4 \%$ the maximum reflectance is present at a temperature of $130^{\circ} \mathrm{C}$. By applying the fluorescent marker at a temperature lower than the temperature of the glass transition of the polyester, the polyester chains are quite rigid, which makes diffusion difficult. Therefore, by increasing the temperature up to $100^{\circ} \mathrm{C}$, the development of amorphous zones in the fibrous structure is favored which facilitates the penetration of dye inside the textile and thus increases fluorescence [36]. A temperature of $130{ }^{\circ} \mathrm{C}$ and $140^{\circ} \mathrm{C}$ can decrease the fluorescence intensity, the quenching phenomenon is observed (figure 5).

The phenomenon of quenching can be explained by the significant collision of fluorescent molecules that will create the $\pi$-staking phenomenon. In fact, this phenomenon corresponds to the non-radiative relaxation of excited electrons towards the fundamental state. This relaxation can be explained by the excimer effect : formation of excimers by the collision of the fluorophore in the excited state and a molecule of the same type not excited [37].

According to the obtained results, two temperature levels $100^{\circ} \mathrm{C}$ and $130^{\circ} \mathrm{C}$ are selected in order to maximize the fluorescence intensity under the UV lamp.

\subsection{Effect of irradiation time on the reflectance}

Figure 6 illustrates the effect of irradiation time on the reflectance of prepared PET fabrics. Three times 5 $\min , 10 \mathrm{~min}$ and $15 \mathrm{~min}$ for two concentrations of the fluorescent product $0.3 \%$ and $0.4 \%$ at $100^{\circ} \mathrm{C}$ and $130^{\circ} \mathrm{C}$ are chosen. The reflectance varies inversely proportional to the irradiation time. This variation is important during the duration of $5 \mathrm{~min}$ to $10 \mathrm{~min}$ and decreases with $15 \mathrm{~min}$ and a stabilization of the reflectance in the time interval from $10 \mathrm{~min}$ to $15 \mathrm{~min}$ is given. In fact, the increase in irradiation time promotes the rise and diffusion of the dye inside the polyester fiber and thus reduces the reflectivity of the textile until it has a maximum dispersion.

According to the figure 7 , it is clear that the effect of time irradiation on the reflectance with a fluorophore concentration of $0.1 \%$ and $0.2 \%$ is less important than that obtained with a concentration of $0.3 \%$ and $0.4 \%$. The intensity of the fluorescence increases by increasing the duration of the irradiation from $5 \mathrm{~min}$ to $15 \mathrm{~min}$. This can result in the accessibility of excited molecules to fluorescent radiative return, which depends on the initial number of molecules in the fundamental state. Therefore, by increasing the application time, the increase of the number of fluorescent molecules in the fiber is promoted. So and 
referring to the previous part, for further investigation the process durations 5 and $15 \mathrm{~min}$ are used and evaluated. In fact, 5 min leads to the maximum reflectance and the minimum fluorescence and vice versa for $15 \mathrm{~min}$.

\subsection{Effect of fluorescein concentration on the reflectance}

Figure 8 shows the variation of the reflectance as a function of the fluorescein concentration from $0.1 \%$ to $0.4 \%$ with a step of $0.1 \%$ at two temperatures $100^{\circ} \mathrm{C}$ and $130^{\circ} \mathrm{C}$.

First of all, the increase of the fluorescein concentration in the bath favors its rise on the textile fiber in a significant way and reduces the reflectance. Then, for an application time of $5 \mathrm{~min}$, the reflectance varies from $44.6 \%$, for a marker concentration of $0.1 \%$ at $100^{\circ} \mathrm{C}$, to a value of $40 \%$ for a marker concentration of $0.4 \%$ at $130^{\circ} \mathrm{C}$. While setting the process duration to $15 \mathrm{~min}$, the reflectance decreases by increasing the concentration of the fluorescent product from $0.1 \%$ to $0.4 \%$ respectively from $45 \%$ to $38 \%$ with a temperature of $100^{\circ} \mathrm{C}$ and varies from $44 \%$ to $35 \%$ for the temperature $130^{\circ} \mathrm{C}$. Finally, in order to minimize the coloration of the samples and to get closer to the reflectance of white polyester, a reduction of the fluorescent tracer concentration interval takes place.

Figure 9 shows the effect of dye concentration on the reflectance of fluorescent polyester according to its emission wavelength. Using a process duration of $5 \mathrm{~min}$ at $100^{\circ} \mathrm{C}$ and $15 \mathrm{~min}$ at $130^{\circ} \mathrm{C}$, the fluorescence increases while amplifying the fluorescein concentration from $0.1 \%$ to $0.3 \%$, then having its maximum at $0.3 \%$ before decreasing at a fluorescein concentration of $0.4 \%$. This can be explained by the increase in the number of excited molecules in the fundamental state by increasing the concentration up to a threshold at which the fluorescence decrease is noticed. This decrease is the result of quenching phenomenon of fluorescence whatever by static inhibition, i.e. the fluorophore establishes a stable and non-fluorescent complex with the dispersed agent and the formation of the complex takes place in the fundamental state and/or either by dynamic inhibition, i.e. the fluorescein is desactivated by contact with the dispersed agent [38].

For the combination of $15 \mathrm{~min}$ and $100^{\circ} \mathrm{C}$, fluorescence follows the increase in concentration from $0.1 \%$ to $0.4 \%$ with a slight variation from $0.3 \%$ to $0.4 \%$. For the last couple (temperature, time) an increase in fluorescence by accentuating the quantity of the fluorescein is noticed, which reaches its maximum at $0.4 \%$.

In order to obtain a good fluorescence under UV lamp and to keep the white color of the fluorescent polyester under daylight, the optimal conditions are a fluorescent concentration of $0.3 \%$, and an irradiation time of $5 \mathrm{~min}$ and $15 \mathrm{~min}$ at $100^{\circ} \mathrm{C}$ and $130^{\circ} \mathrm{C}$.

\subsection{Fluorescence Imaging of treated Polyester Fabrics}

Table 2 illustrates pictures of non-treated polyester and fluorescent samples under visible light and under UV lamp excitation at $465 \mathrm{~nm}$ using a light cabin. 
It is obvious that by increasing the process duration and process temperature of application the textile becomes a little colored under daylight and gives a yellow-greenish coloration when it is excited under a UV lamp.

\section{Table 2: Photographs of polyester fabrics before and after dyeing. The photographs are taken under different illumination conditions.}

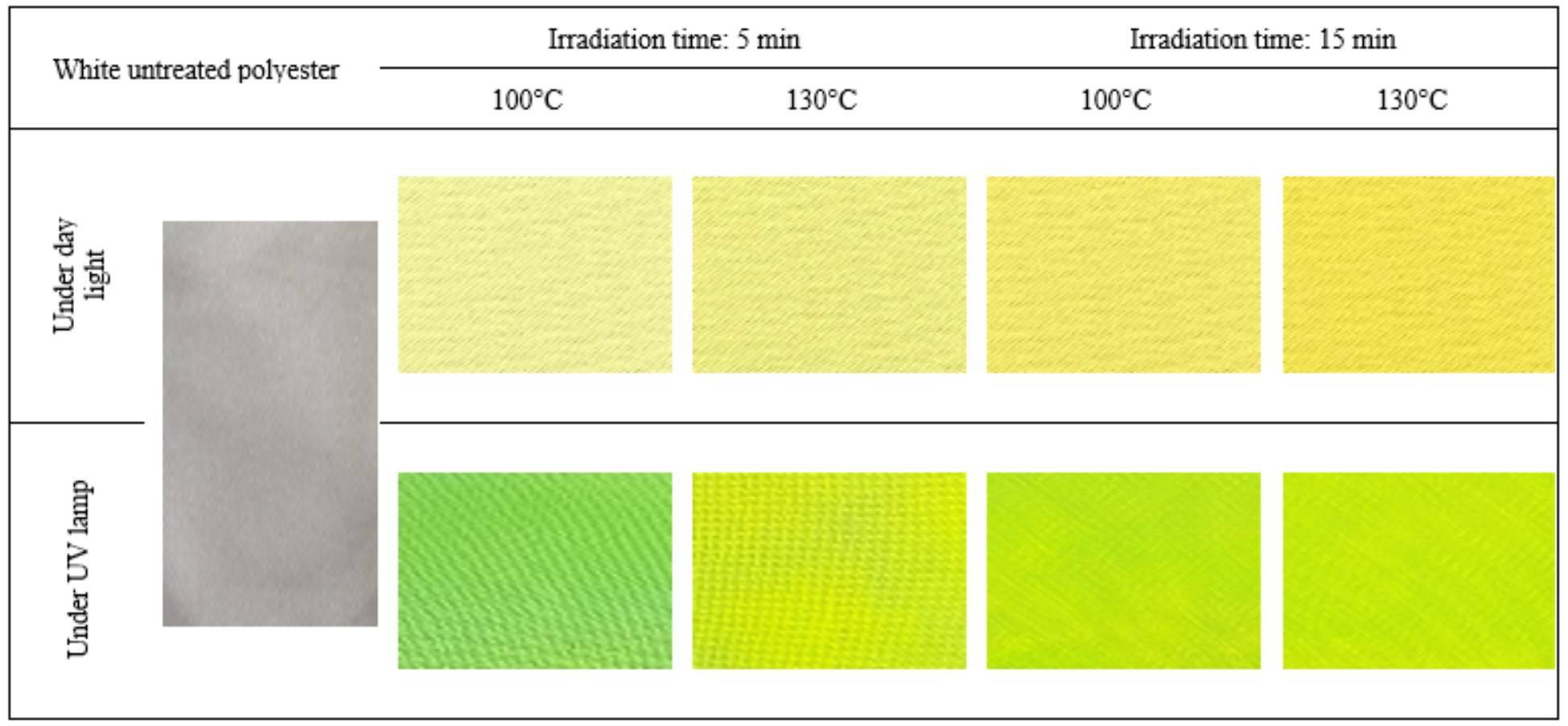

The commercial fluorescent dyes recommended for textiles are often criticized for light fastness properties which are unable to meet the standards required by more demanding applications. The chemical skeleton of the dye used in actual study is rich of double and single bonds which makes it sensitive to light [40]. However, the use of UV absorber overlayers can produce a fluorescent colour with reasonable light stability [31].

In order to improve the durability of the treatment against light, a UV absorber is introduced in the bath of the fluorescent solution.

\subsection{The addition of UV absorber}

UV absorbers are colorless organic/inorganic compounds that exhibit strong absorption in the UV wavelength range between $290 \mathrm{~nm}$ and $360 \mathrm{~nm}$ [41-46]. Once incorporated into fibers, they convert electronic excitation energy into thermal energy. When a UV absorber is excited by high-energy UV radiation and the short-wavelength UV absorber, the absorbed energy can be dissipated as longerwavelength radiation [42]. Noting that an effective UV absorber must be able to absorb across the spectrum to remain stable against ultraviolet radiation and dissipate the absorbed energy to avoid degradation or color loss [39]. Indeed, many UV absorbers reduce the bleaching effect of common fluorescent brighteners (FAs) because their efficiency in the UV range reaches the efficiency range of these 
brighteners. For these reasons, it is necessary to use broadband UV absorbers that do not extend into the absorption band of the fluorescent brightener and are covalently bound to the treated tissue [35].

From a chemical point of view, several classes of UV absorbers are available. Important groups of UV absorbers are: 2-hydroxybenzophenones, 2-hydroxyphenylbenzotriazoles, 2 hydroxyphenyl-s-triazines $[41,42]$. For the evaluation of a UV-absorber finishing realized by a microwave-assisted finishing process, polyester woven materials are treated with the UV absorber Tanuval UVL from Tanatex, Netherlands. The finishing process is performed using a focused microwave synthesis system. The UV-light contains wavelength below $400 \mathrm{~nm}$. For this, the efficiency of the UV-protective finishing is characterized with transmission spectra presenting the diffuse transmission of UV-light. When radiation strikes a fibre surface, it can be reflected, absorbed, transmitted through the fibre or pass between fibres (Figure 10) [47]. The minimum transmission defines the UV protection efficiency. The lower transmission value, the more effective UV absorber is. The application of a UV absorber decreases the transmission value. The addition of UV absorber to the bath has a lesser influence on the color of the fluorescent samples and leads to a yellowish color [48].

According to its technical data sheet four concentrations of UV absorber from $0.5 \%$ to $2 \%$ with a step of $0.5 \%$ are used. The study of this treatment is done by measuring the reflectance, fluorescence, and transmission of the textile support.

\subsubsection{Effect of UV absorber on the reflectance value}

The curve above represents the evolution of the reflectance as a function of UV absorbers concentration at $100^{\circ} \mathrm{C}$ and $130^{\circ} \mathrm{C}$ for 5 and $15 \mathrm{~min}$ (Figure 11).

It is clear that the addition of UV absorber influences the final coloration of the textile support. This treatment decreases the reflectance once the UV absorber concentration is increased. The evolution of the curves is identical, in fact with a temperature of $100^{\circ} \mathrm{C}$ pendant a radiation time of $5 \mathrm{~min}$, the reflectance decreases from $42 \%$ to $36 \%$ by adding to the fluorescent bath a concentration of $0.5 \%$ UV absorber. This decrease is explained by the yellow coloration caused by this absorber. In fact, some UV absorbers produce an undesired yellowish color on treated fabrics, adversely affecting the dyeings obtained. By passing from a concentration of UV absorber from $0.5 \%$ to $2 \%$ the reflectance decreases slightly and then stabilizes.

From this figure 9, it can also be noted that with the maximum of the temperature and during the minimum of process duration, the curve obtained is superimposed on that obtained with the minimum of the temperature and the maximum of duration.

With a temperature of $130{ }^{\circ} \mathrm{C}$ and process duration of 15 minutes, the coloration of the textile fabric is outstanding and the reflectance varies from $38 \%$ to $31 \%$ by adding $2 \%$ of UV absorber to the bath.

\subsubsection{Effect of UV absorber on the fluorescence properties}

Page 12/34 
Figure 12 shows the variation of the reflectance as a function of the UV absorber concentration from $0.5 \%$ to $2 \%$ with a temperature of $100^{\circ} \mathrm{C}$ for 5 and $15 \mathrm{~min}$.

The intensity of fluorescence varies inversely with the increase of the UV absorber concentration. Indeed, for a process duration of $5 \mathrm{~min}$, the reflectance varies from $100 \%$ without the addition of UV absorber to $92 \%$ for a UV absorber concentration of $2 \%$. This variation is more accentuated in the concentration range of $1.5 \%$ to $2 \%$ due to the increase of the number of UV absorber molecules in the fluorescent bath. This increase facilitates and favours the collision between fluorescein and UV absorber either by establishing a non-fluorescent complex stable in its fundamental state and in this case it can be spoken of static quenching, or by deactivating the fluorophore by subbing contact with the UV absorber molecule and in this case this phenomenon of dynamic quenching will be in place.

It is clear that with the addition of a concentration of $0.5 \%$ UV absorber the reflectance curve gives us the minimum variation of fluorescence compared to the treated sample without UV absorber. In fact, for an irradiation time of $5 \mathrm{~min}$ and $15 \mathrm{~min}$ the difference in reflectance compared to the fluorescent fabric without UV absorber is $0.51 \%$ and $0.91 \%$ respectively.

\subsubsection{Effect of the concentration of UV absorber on the transmission}

The effect of adding UV absorber to the dye bath is well confirmed by observing the figure 13 illustrating the evolution of transmission as a function of wavelength.

When analyzing the different transmission spectra, it is obvious, that the treatment with an UV-absorber generally decreases the transmission of the UV-light in comparison to the untreated reference. The untreated reference sample has no UV-protective function for a range of wavelength from $400 \mathrm{~nm}$ to nearly $300 \mathrm{~nm}$. However, the transmission decreases to nearly zero around $300 \mathrm{~nm}$ wavelength. A reason might be the aromatic structure of polyester that offers certain UV-protection [36]. Further, all samples finished with the UV-absorber Tanuval, no matter which finishing process is applied, show a decreasing transmission in the range of wavelength from $400 \mathrm{~nm}$ to $350 \mathrm{~nm}$, to nearly zero at $350 \mathrm{~nm}$.

A recap of the results reached with different parameters shows that for a process duration of $5 \mathrm{~min}$, the transmission decreases by increasing the UV absorber concentration from $0.5 \%$ to $1 \%$ and then stabilizes and tends to zero for the concentration range from $1 \%$ to $2 \%$. The only difference compared to the irradiation time of $5 \mathrm{~min}$ is that the UV absorber activity range widens and tends towards the visible region up to $380 \mathrm{~nm}$ while passing from a concentration of $0.5 \%$ to $2 \%$.

For the application of UV absorber on the textile support, with a concentration of $0.5 \%$ and a time of 5 min and $15 \mathrm{~min}$, the maximum reflectance, the maximum fluorescence, and a more acceptable transmission value are obtained. Therefore, the evaluation of the washing fastness and light fastness of the fluorescent textile support in the presence of UV absorber is made by selecting the sample prepared with $0.3 \%$ fluorescent tracer concentration and $0.5 \% \mathrm{UV}$ absorber concentration for $5 \mathrm{~min}$ and $15 \mathrm{~min}$ at $100^{\circ} \mathrm{C}$.

\subsection{Fluorescence Imaging of treated Polyester Fabrics with UV absorber}


Table 3 illustrates pictures of non-treated polyester and fluorescent samples under daylight and under UV lamp excitation using a light cabin. The irradiation time of the treated samples is 5 min.

Table 3: Photographs of polyester fabrics dyed without and with UV absorber at different concentrations

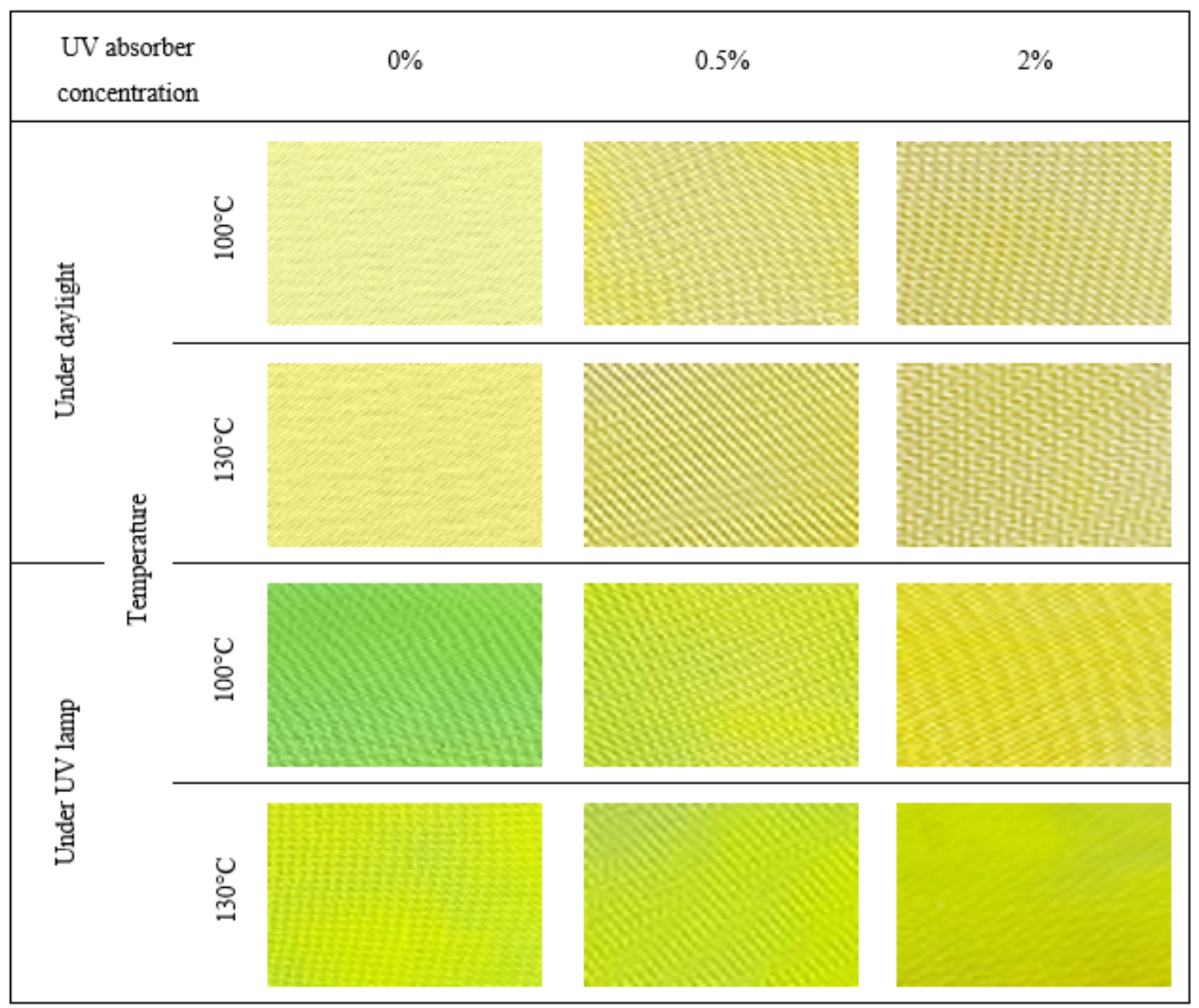

It is clear that under the daylight, the addition of UV absorber causes an additional yellowish coloration on the surface of the treated textile. This coloration slightly decreases the intensity of fluorescence seen under UV lamp.

\subsection{Surface Morphologies of fluorescent Polyester Fabrics in presence of UV absorber}

To verify the existence of the anti-counterfeit product at the surface of polyester fabric, treated samples are examined by scanning electron microscope (SEM) (Figure 14).

The SEM analysis shows the presence of the fluorescent agent on the surface and between the fibers of the treated polyester.

3.8 Effect of the addition of UV absorber on light and wash fastness 
Generally, to study the effectiveness of such a treatment, it is obviously necessary to study its durability over time. Therefore, the washing and light fastness of prepared fluorescent samples is evaluated.

\subsubsection{Washing fastness}

The evaluation of the washing fastness is given in the Table 4. The samples to be evaluated are treated with a fluorescent marker concentration of $0.3 \%$ in the presence of $0.5 \% \mathrm{UV}$ absorber at a heating temperature of $100^{\circ} \mathrm{C}$ for 5 and $15 \mathrm{~min}$.

The results indicate excellent fastness properties of the dyed samples with fluorescent tracer in the presence of UV absorber. By comparing them with the results obtained without UV absorber, it can be said that the washing fastness is slightly influenced by the addition of UV absorber. This can be explained by the presence of dispersing agent in the UV absorber composition responsible for the best dispersion of fluorescent tracer in the dyeing solution and thus a better affinity towards the textile fiber.

\section{Table 4: Evaluation of washing fastness}

\begin{tabular}{|lllll|}
\hline $\begin{array}{l}\text { Fluorescein } \\
\text { concentration }\end{array}$ & $\begin{array}{l}\text { Irradiation } \\
\text { time }\end{array}$ & Temperature & Greyscale & \\
\hline $0.3 \%$ & $\begin{array}{l}\text { Without UV } \\
\text { absorber }\end{array}$ & $\begin{array}{l}\text { With UV } \\
\text { absorber }\end{array}$ \\
& $5 \mathrm{~min}$ & $100^{\circ} \mathrm{C}$ & $4 / 5$ & $4 / 5$ \\
\hline $15 \mathrm{~min}$ & $100^{\circ} \mathrm{C}$ & 5 & 5 \\
\hline
\end{tabular}

\subsubsection{Daylight fastness}

The evaluation of the light fastness is given in Table 5. The samples to be evaluated are treated with a fluorescent marker concentration of $0.3 \%$ in the presence of $0.5 \% \mathrm{UV}$ absorber at a heating temperature of $100^{\circ} \mathrm{C}$ for 5 and $15 \mathrm{~min}$.

\section{Table 5: Evaluation of light fastness}

\begin{tabular}{lllllll}
$\begin{array}{l}\text { Fluorescein } \\
\text { concentration }\end{array}$ & $\begin{array}{l}\text { Irradiation } \\
\text { time }\end{array}$ & Temperature & \multicolumn{4}{l}{$\begin{array}{l}\text { Fluorescence life time } \\
\text { Blue scale }\end{array}$} \\
\cline { 3 - 7 } & & $\begin{array}{l}\text { Without UV } \\
\text { absorber }\end{array}$ & $\begin{array}{l}\text { With UV } \\
\text { absorber }\end{array}$ & $\begin{array}{l}\text { Without UV } \\
\text { absorber }\end{array}$ & $\begin{array}{l}\text { With UV } \\
\text { absorber }\end{array}$ \\
\hline $0.3 \%$ & $5 \mathrm{~min}$ & $100^{\circ} \mathrm{C}$ & $6 \mathrm{~h}$ & $8 \mathrm{~h}$ & 4 & $4 / 5$ \\
\cline { 2 - 6 } & $15 \mathrm{~min}$ & $100^{\circ} \mathrm{C}$ & $6 \mathrm{~h}$ & $8 \mathrm{~h}$ & 4 & $4 / 5$
\end{tabular}

The addition of a UV absorber to the fluorescent bath improves the light fastness of the dyed samples. The durability of such a fluorescent treatment after exposure to light reaches 8 hours and 6 hours without UV absorber. 
The blue scale with the values found, informs us about the sensitivity of fluororesin to light. Despite the presence of a UV absorber, this value is slightly improved. This can be explained by the photobleaching phenomenon of most organic fluorophores.

\section{Conclusion}

In this study, organic fluorescent molecule was successfully incorporated into polyester fabric by microwave irradiation technique for use as an anti-counterfeiting. A highly fluorescent, inexpensive and ecological fluorophore is applied to a polyester fabric in the presence of a dispersed agent and UV absorber. The fluorescent samples are characterized by scanning electron microscopy SEM, reflectance and fluorescence analyses, which revealed the presence of fluorescein on the polyester surface.

The optimal conditions for obtaining an anti counterfeiting fluorescent polyester fabric are to use a bath concentration of $0.3 \%$ on fluorescein in the presence of $0.5 \%$ UV absorber concentration for 5 minutes at $100^{\circ} \mathrm{C}$. In fact, such a process guarantees an adequate fluorescence intensity and good wash stability with a light resonable solidity.

The diffusion of UV absorber into the polyester fiber improves the light fastness of a value of $25 \%$. Their addition in the bath has the role not only to improve the light fastness of the fluorescent logos but to obtain a textile with protective properties against UV light. Improving the light fastness of polyester fluorescent logos can be solved by the use of other UV absorbers via several techniques.

It should be noted that a small amount of tracer is adequate to obtain sufficient fluorescence for antifraud applications, which makes this product economically advantageous for industrial exploitation.

Finally, for better authentication of textile products from the point of view durability of the fluorescent effect, clothing storage conditions are proposed. The use of black labels covered by plastic bags can be a solution to protect fluorescent logos against moisture and prolonged exposure under daylight.

\section{Declarations}

The authors have no conflicts of interest to declare that are relevant to the content of this article.

Funding: The authors did not receive support from any organization for the submitted work

\section{Conflicts of interest/Competing interests}

Financial interests: The authors declare they have no financial interests.

Non-financial interests: None

Availability of data and material: The datasets generated during and/or analysed during the current study are available from the corresponding author on reasonable request. 
Code availability: Not applicable.

Author's contributions: All authors contributed to the study conception and design. Material preparation, data collection and analysis were performed by all authors. The first draft of the manuscript was written by Fredj Saad and all authors commented on previous versions of the manuscript. All authors read and approved the final manuscript.

Ethics approval: All the authors mentioned in this manuscript have agreed for authorship, read and approved the manuscript.

Consent to participate: All authors given consent for participation.

Consent for publication: All authors have given their consent for the subsequent publication of the manuscript.

Acknowledgements: The Ministry of Higher Education and Scientific Research of Tunisia supported this study. The author would like to express sincere gratitude to the direction and the staff of Faculty Textile and Clothing Technology in Monchengladbach for their support and help.

\section{References}

1. Taeyoung K, Sheldon XDT, and Chase C, Zeyu S (2018) Detection of counterfeited ICs via on-chip sensor and post-fabrication authentication policy. Integr. VLSI J 63:31-40.

2. Hendrick E, Frey M, Herz E, Wiesner U (2010) Cellulose Acetate Fibers with Fluorescing Nanoparticles for Antcounterfeiting and pH-sensing Applications. J Eng. Fiber Fabr 5:21-

30. https://doi.org/10.1177/155892501000500103

3. Andres J, Hersch RD (2014) Color reproduction of authenticable luminescent backlit transmissive color image. Color Res. Appl. 39:331-340, 2014. https://doi.org/10.1002/col.21815

4. Minli Y, Junjie Z, Yuan H, Zhenfeng D, Min L, Feng X (2015) Inkjet printing of upconversion nanoparticles for anti-counterfeit applications. Nanoscale 7:4423-4431.

https://doi.org/10.1039/C4NR06944G

5. Xiaowan L, Yingcheng $H$ (2019) Luminescent films functionalized with cellulose nanofibrils/CdTequantumdots for anti-counterfeiting applications. Carbohyd. Polym. 203:167175. https://doi.org/10.1016/j.carbpol.2018.09.028

6. Chang K, Liu Z, Chen H, Sheng L, Zhang SX, Chiu DT, Yin T, Wu C, Qin W (2014) Conjugated polymer dots for ultra-stable full-color fluorescence patterning. Small 10:4270-4275.

7. Hongren L, Xingjia G, Jun L, Feng L (2016) A synthesis of fluorescent starch based on carbon nanoparticles for fingerprints detection. Opt. Mater. Vol. 16:404- 
410. http://dx.doi.org/10.1016\%2Fj.optmat.2016.08.010

8. Sergii K, Yu W, Kateřina P, Radek Z (2018) Carbon dot fluorescence life time encoded anti-counterfeiting. ACS Appl. Mater. Interfaces 10:29902-29908. https://doi.org/10.1021/acsami.8b11663

9. Bin S, Houyu W, Yiling Z, Binbin C, Yuanyuan S, Yao H (2018) Fluorescent and magnetic anticounterfeiting realized by biocompatible multifunctional silicon nanoshuttle-based security ink. Nanoscale 10:1617-1621. https://doi.org/10.1039/C7NR06337G

10. Julien A, Roger DH, Jacques-Edouard M, Anne-Sophie C (2014) A new anti-counterfeiting feature relying on invisible luminescent full color images printed with lanthanide based inks. Adv. Funct. Mater. 24:5029-5036. https://doi.org/10.1002/adfm.201400298

11. Miao Z, Peng X, Xiaohua G, Zongren L, Mingming G, Bowen C (2010) Synthesis, characterization and fluorescence properties of a novel rare earth complex for anti-counterfeiting material. J. Rare Earth 10:7578. https://doi.org/10.1016/S1002-0721(10)60359-6

12. Zhao Z, Hui C, Bailiang X, Sufeng Z, Xinping L, Wai-Kwok W, Kecheng L, Xunjin Z (2018) Near-infrared and visible dual emissive transparent nanopaper based on $\mathrm{Yb}(\mathrm{III})$-carbon quantum dots grafted oxidized nano fibrillated cellulose for anti-counterfeiting applications. Cellulose 25:377-

389. https://link.springer.com/article/10.1007/s10570-017-1594-1

13. Pinchuk LS, Goldade VA, Kuz'menkova NV, Sytsko VE, Lobanovskii LS, Drozd ES (2013) Modification of polyester fibers for protection of securities. Fibre Chem. 44:273-279.

14. Goldade VA, Kuzmenkova NV, Sytsko VE (2015) Coloration of Polyester Fibers for Securities Protection from Counterfeit. J. Res. Updates Polym. Sci. 12:15-23. https://doi.org/10.6000/1929-5995.2015.04.01.2

15. Jianbin L, Yixi Z, Le W, Tianliang Z, Naoto H, Rong-Jun X (2018) Achieving multicolor long lived luminescence in dye encapsulated metal-organic frameworks and its application to anti-counterfeiting stamps. ACS Appl. Mater. Interfaces 10 :1802-1809. https://doi.org/10.1021/acsami.7b13486

16. Gordon N (2002) Application of microencapsulation in textiles. Int. J. Pharm. 242 :55-62. https://doi.org/10.1016/s0378-5173(02)00141-2

17. Denis D, Denis C, Jean-Jacques P (2012) Traçabilité et authentification des produits textiles dans la filière THD. France

18. Jishu Z, Mingqiao G (2011) Effecting factors of the emission spectral characteristics of rare-earth strontium aluminate for anti-counterfeiting application. J. Lumin 131:1765-1769. https://doi.org/10.1016/j.jlumin.2011.04.021

19. Jishu Z, Mingqiao G (2012) Effects of transparent inorganic pigment on spectral properties of spectrum-fingerprint anti-counterfeiting fiber containing rare earth. J. Rare Earth. 31:952 - 957. 
https://doi.org/10.1016/S1002-0721(12)60160-4

20. Qiao X, Yan B (2009) Chemically bonded assembly and photophysical properties of luminescent hybrid polymeric materials embedded into silicon-oxygen network and carbon unit. Journal of Organometallic Chemistry 694:3232. https://doi.org/10.1016/j.jorganchem.2009.06.019

21. Xi P, Wang L, Huang X (2005) Synthesis and characterization of Eu3+ quaternary complex with 2,2dihydroxymethyl propionic acid. J. of the Chinese Rare Earth Society (in Chin.) 23.

22. Gilmar PT, Hermi FB, Sandra AS, Maria ASO, Maria CFCF (2003) Preparation and optical properties of trivalent europium doped into cordierite using the sol-gel process. J. Solid State Chem. 171:375-381. https://doi.org/10.1016/S0022-4596(02)00216-5

23. Thomas AR, Florestan B, Michael SR (2013) Fluorescein Derivatives in Intravital Fluorescence Imaging. Cells 2:591-606. https://dx.doi.org/10.3390\%2Fcells2030591

24. Ghulam S, Aamer S, Pervaiz AC (2018) Review on the Recent Trends in Synthetic Strategies and Applications of Xanthene Dyes. Mini-Rev. Org. Chem. 14:1-32.

https://doi.org/10.2174/1570193X14666170518130008

25. Ghini G, Tron C, Giannetti A, Puleo GL, Luconi L, Amadou J, Giambastiani G, Baldini G (2013) Carbon nanotubes modified with fluorescein derivatives for $\mathrm{pH}$ nanosensing. Sens. Actuator B-Chem. 179:163169. https://doi.org/10.1016/j.snb.2012.10.022

26. Luke DL, Thomas JR, and Ronald TR (2007) Tuning the pKa of fluorescein to optimize binding assays. Anal. Chem. 79:6775-6782. https://doi.org/10.1021/ac070907g

27. Fereshteh N, Ali F, Farrokh G (2014) Solvatochromic and preferential solvation of fluorescein in some water-alcoholic mixed solvents. J. Mol. Liq. 90:126-132. https://doi.org/10.1016/j.molliq.2013.10.028

28. Baatout K, Saad F, Baffoun A, Mahltig B, Kreher D, Jaballah N, Majdoub M (2019) Luminescent cotton fibers coated with fluorescein dye for anti-counterfeiting applications. International Journal of Materials Chemistry and Physics 234:304-310. https://www.cheric.org/research/tech/periodicals/doi.php? art_seq $=1773559$

29. Thermo Fisher Scientific (2010) Molecular Probes ${ }^{T M}$ Handbook A Guide to Fluorescent Probes and Labeling Technologies. US

30. Kappe CO, Dallinger D (2009) Controlled microwave heating in modern organic synthesis: highlights from the 2004-2008 literature. Mol. Divers 13:71-193. doi:10.1007/s11030-009-9138-8

31. Erhan Ö, Yeşim B, Nihal S (2013) Microwave-assisted dyeing of poly(butylene terephthalate) fabrics with disperse dyes. Color. Technol. 129:125-130. http://dx.doi.org/10.1111/cote.12014 
32. Al-Mousawi SM, El-Apasery MA, Elnagdi MH (2013) Microwave Assisted Dyeing of Polyester Fabrics with Disperse Dyes. Molecules 18:11033-11043. https://doi.org/10.3390/molecules180911033

33. Choudhury AKR (2011) Pre-treatment and preparation of textile materials prior to dyeing. In: Clark M Handbook of textile and industrial dyeing. Woodhead Publishing, India, pp 64-149

34. Lingzhi W,Yaofeng S, Jinlong Z, Masakazu A (2016) Study on the fluorescence properties of fluorescein dye incorporated into SBA-15. Opt. Mater 28:1232-

1234. https://doi.org/10.1016/j.optmat.2005.08.005

35. Christie RM (2011) fluorescent dyes. In: Clark M Handbook of textile and industrial dyeing. Woodhead Publishing, UK, pp 562-587

36. Azizul I, Rashaduzzaman, Mahbubur R, Jagannath B, Elias K (2016) A Study on the Effects of Material to Liquor Ratio on the Colorfastness of Synolon Yellow EXW Fluorescent Disperse Dye. International Journal of Materials Science and Applications 5:248-253. 10.11648/j.jjmsa.20160506.13

37. Gulrajani ML (2011) Disperse dyes. In: Clark M Handbook of textile and industrial dyeing. Woodhead Publishing, Delhi, India, pp 365-394

38. Lakowicz JR (2006) Quenching of Fluorescence. In: Principles of Fluorescence Spectroscopy, $3^{\text {rd }}$ ed. Springer, Boston, MA, USA, pp 277-330

39. Mallik SK, Arora T (2003) UV radiations: problems and remedies. Man Made Text. India. 46:164-169.

40. Joseph R. Lakowicz (2006) Fluorophores. In: Principles of fluorescence spectroscopy, $3^{\text {rd }}$ ed..

41. Das BR, Ishtiaque SM, Rengasamy RS, Hati S, Kumar A (2010) Ultraviolet Absorbers for Textiles. Research Journal of Textile and Apparel.14:42-50. https://doi.org/10.1108/RJTA-14-01-2010B005

42. Gantz GM, Sumner WG (1957) Stable Ultraviolet Light Absorbers. Textile Res. J 27:244-251. https://doi.org/10.1177\%2F004051755702700310

43. Holme I (2003) UV absorbers for protection and performance. Int. Dyer. 189:9-10.

44. Rupp J, Bohringer A, Yonenaga A, Hilden J (2001) Textiles for protection against harmful ultraviolet radiation. Int. Text. Bull. 6:8-20.

45. Kirti G, Asimananda K, Bijayalaxmi S (2018) Developing eco-friendly uv protective textiles based on plant extract. JETIR 5:461-468.

46. Omer KA, Tao Zhao (2017) Developing UV protection of cotton fabric (a review). The Journal of The Textile Institute 108(12): 2027- 2039 
47. Saravanan D (2007) UV Protection Textile Materials. AUTEX Research Journal 7:53-62.

48. Liang H, Guoliang G, Harold SF, Wei J, Meifen C, Defeng Z (2010) Studies involving reactive dyes containing a benzophenone ultraviolet absorber. Color.Technol. 127:47-54.

\section{Figures}

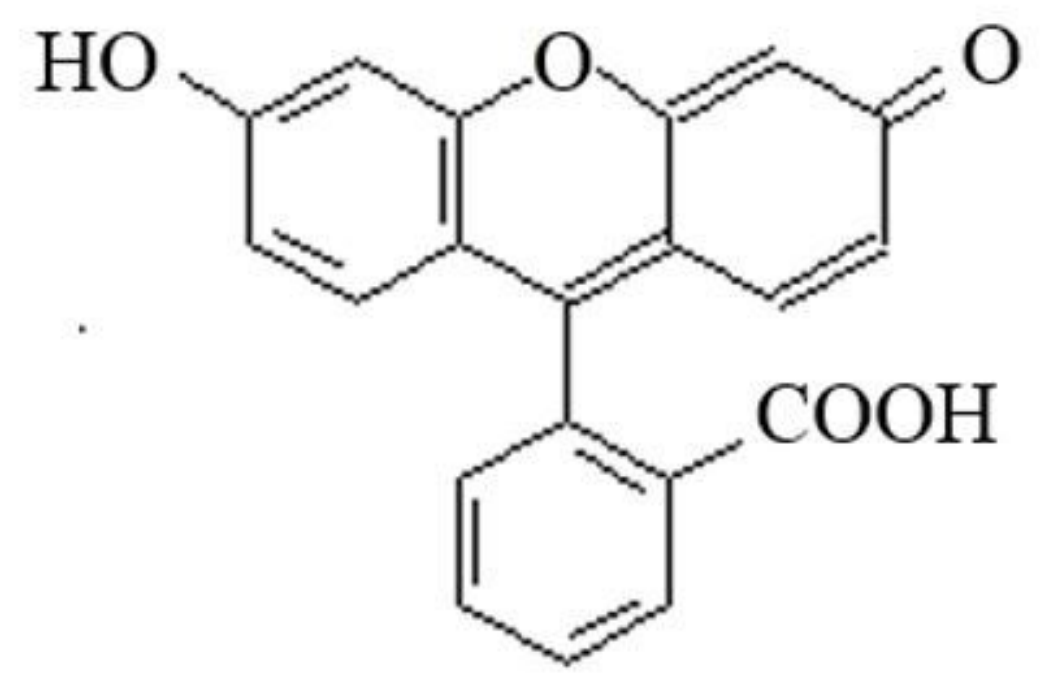

\section{Figure 1}

Chemical structure of fluorescein at $\mathrm{pH}=4.5$ 


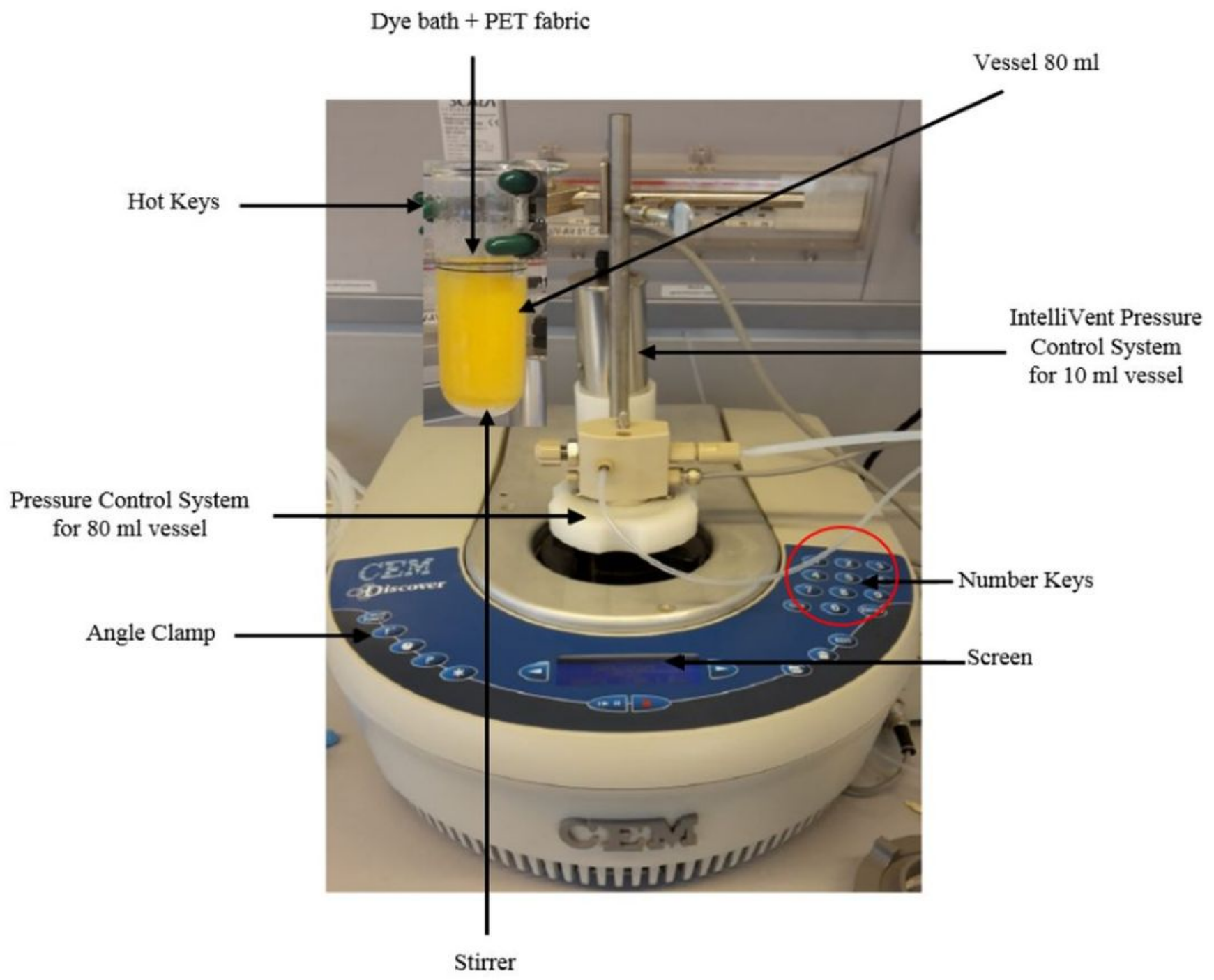

Figure 2

Focused Microwave Synthesis System, Model Discover, manufacturer: CEM 


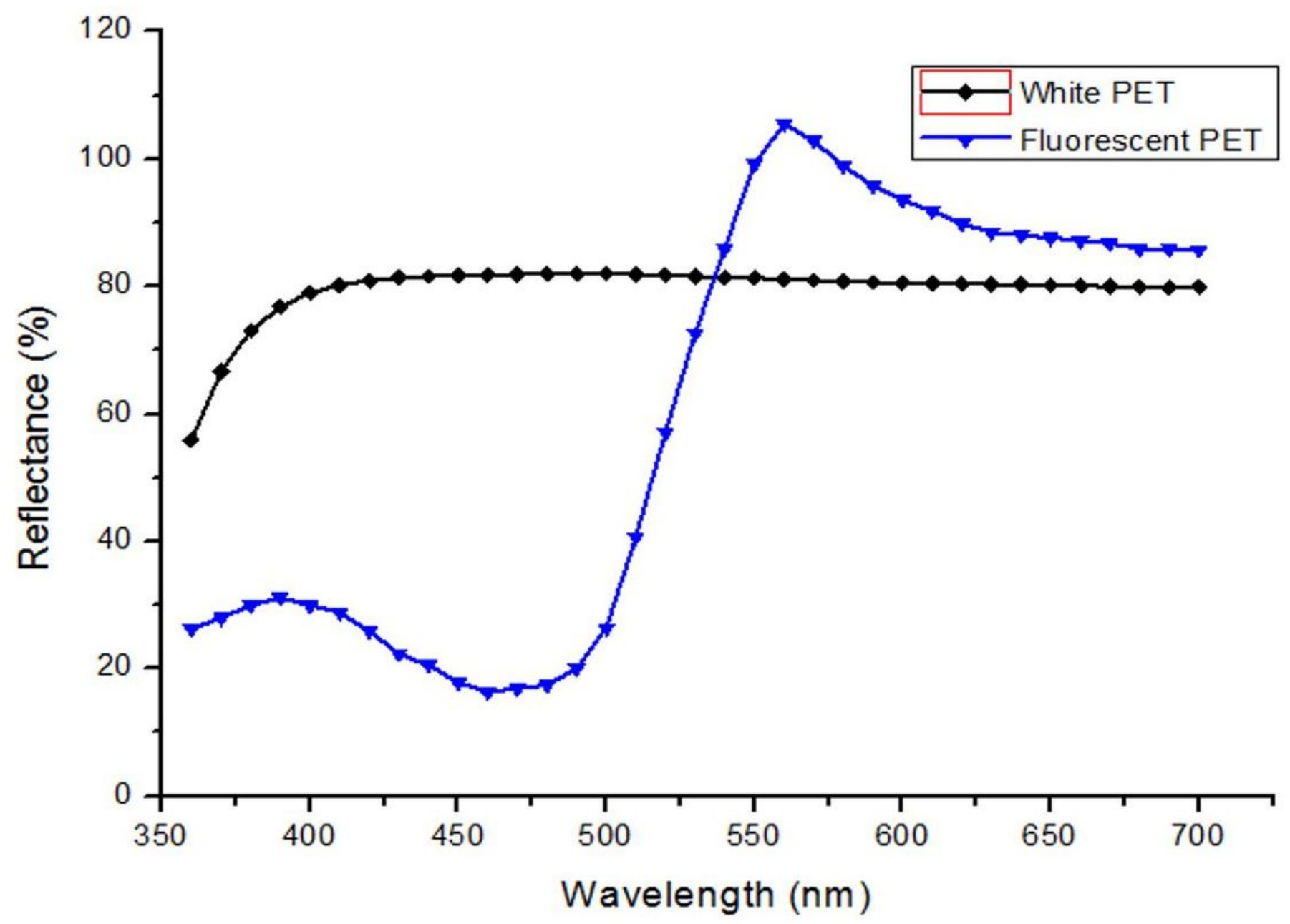

Figure 3

Curve of reflectance as a function of wavelength (in black: untreated white poleyster and in blue: fluorescent sample, treated with a dye concentration of $0.3 \%$ at $130{ }^{\circ} \mathrm{C}$ for $5 \mathrm{~min}$ ) 
(a)

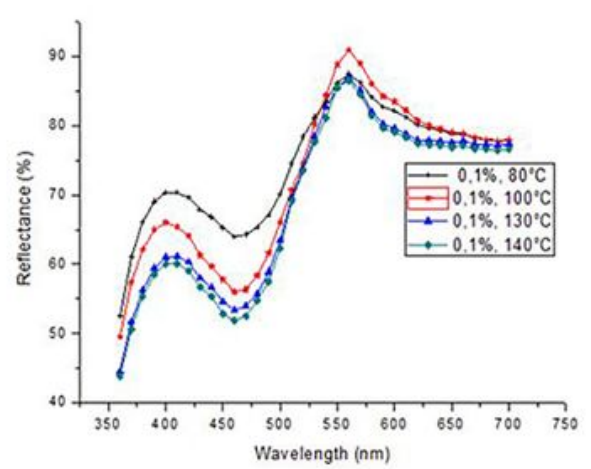

(b)

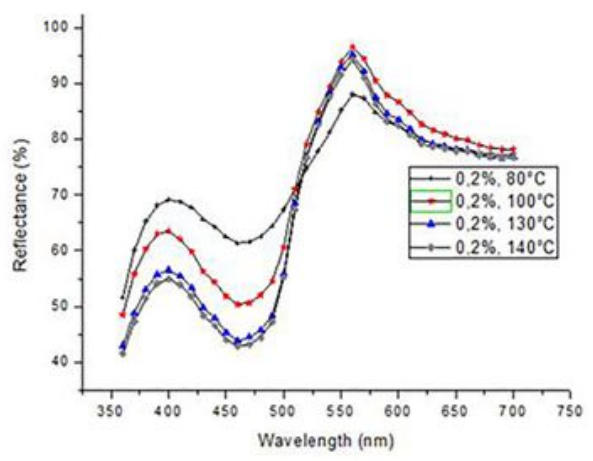

(c)

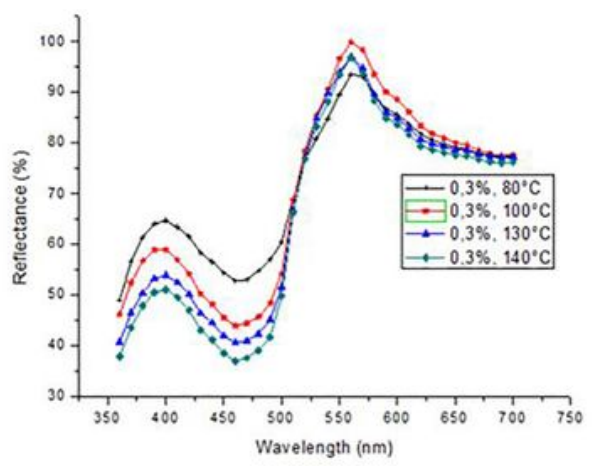

(d)

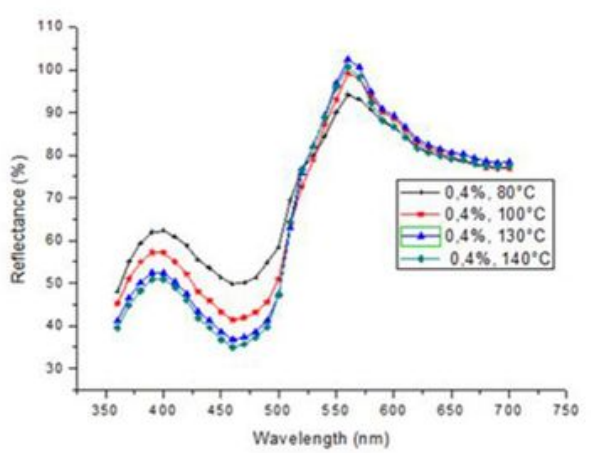

\section{Figure 4}

Effect of temperature and dye concentration on the reflectance at $460 \mathrm{~nm}$ absorption wavelength 


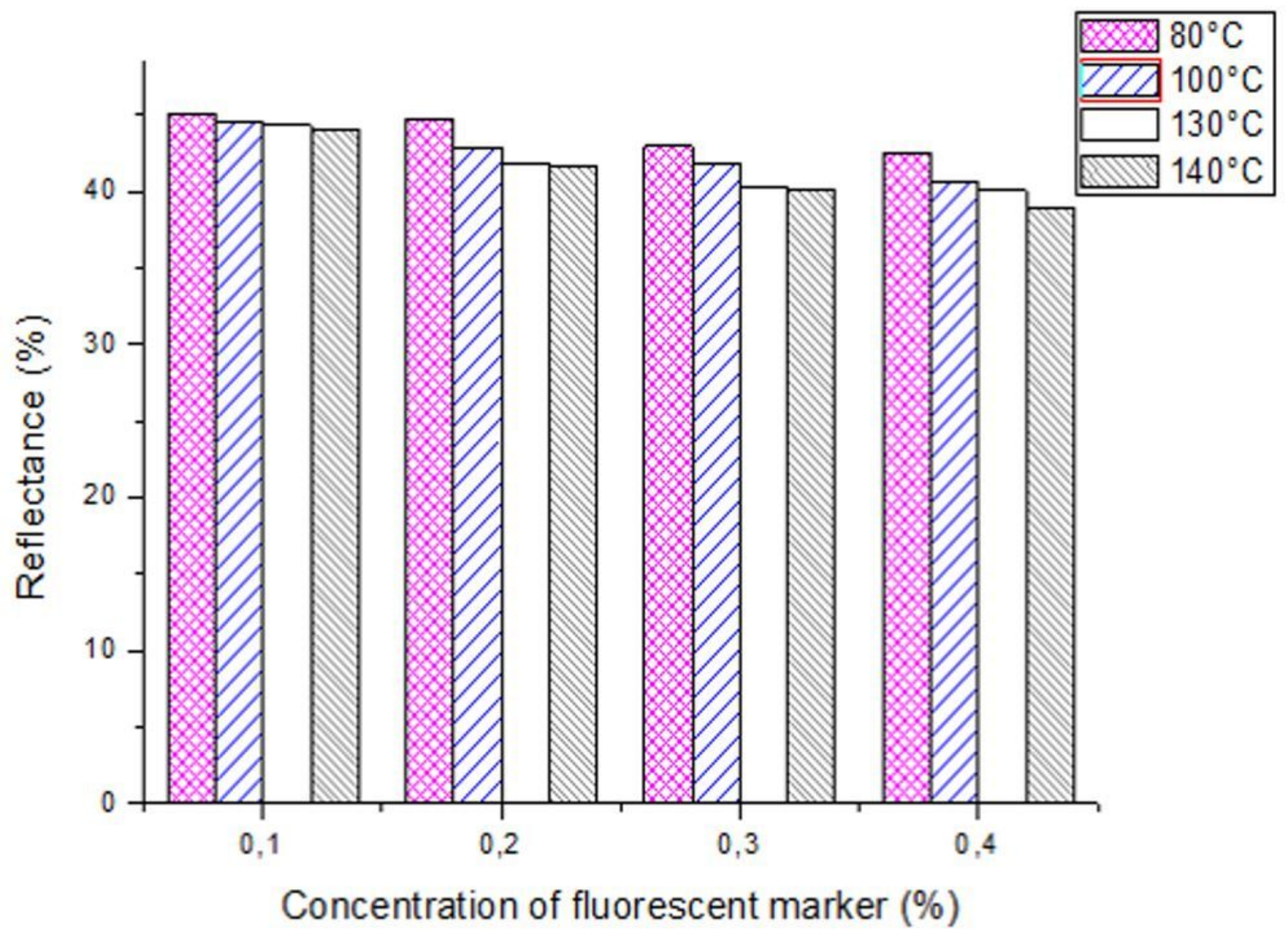

Figure 5

Effect of temperature and dye concentration on the reflectance at $560 \mathrm{~nm}$ emission wavelength 
(a)

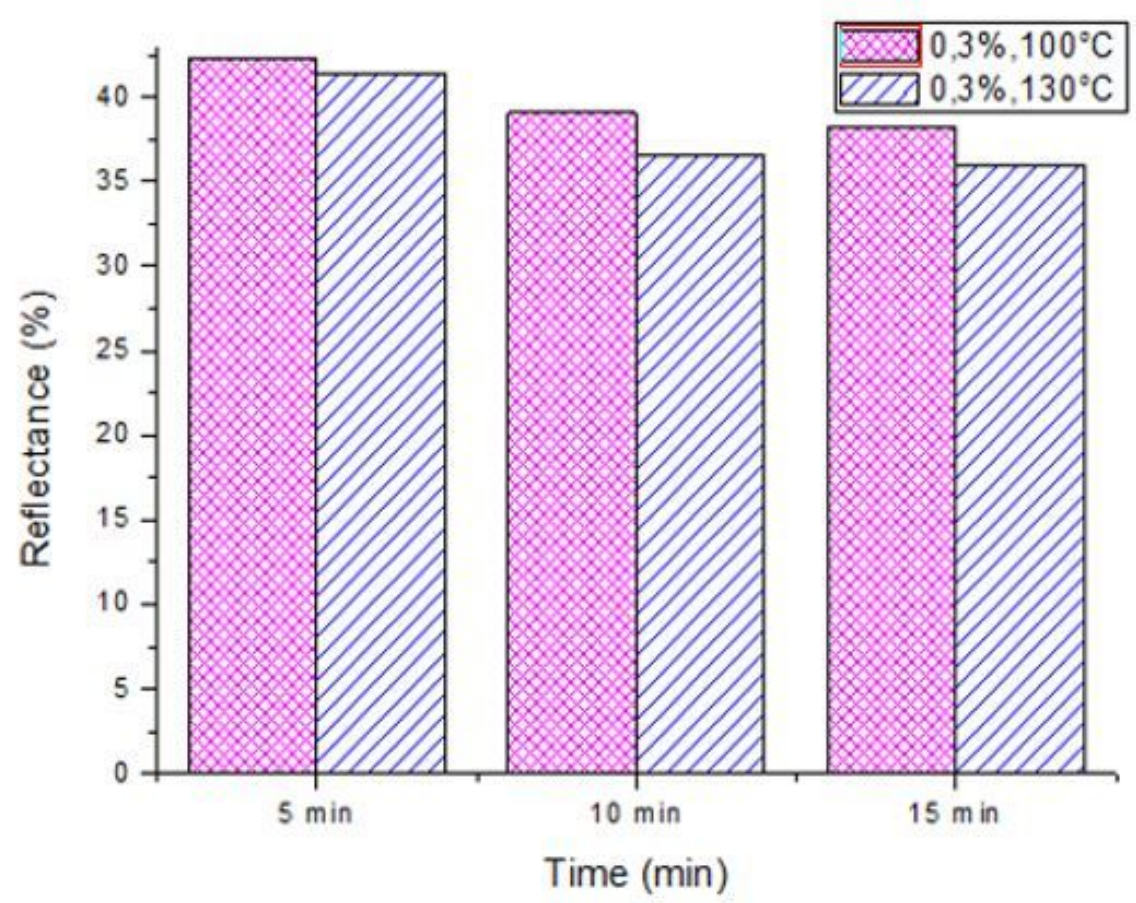

(b)

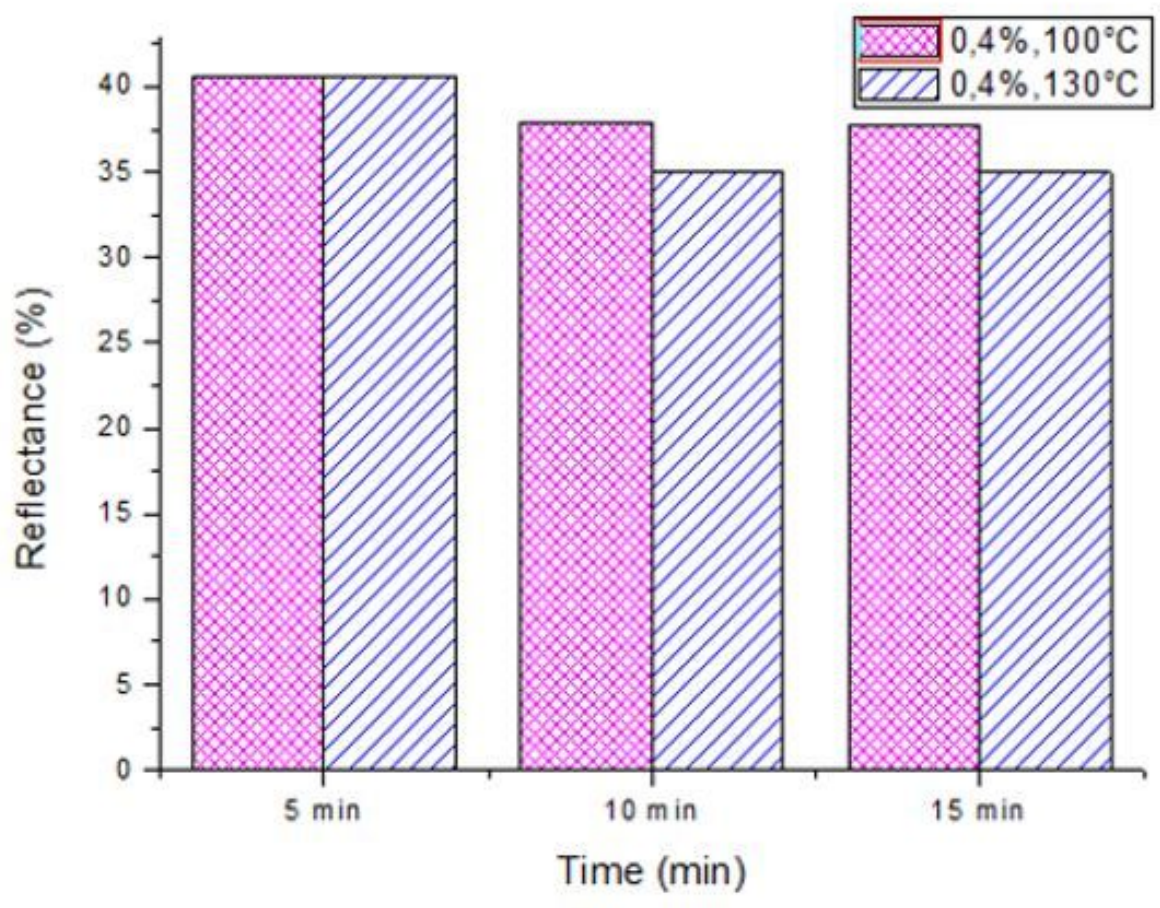

Figure 6

Effect of irradiation time on the reflectance at $460 \mathrm{~nm}$ absorption wavelength 


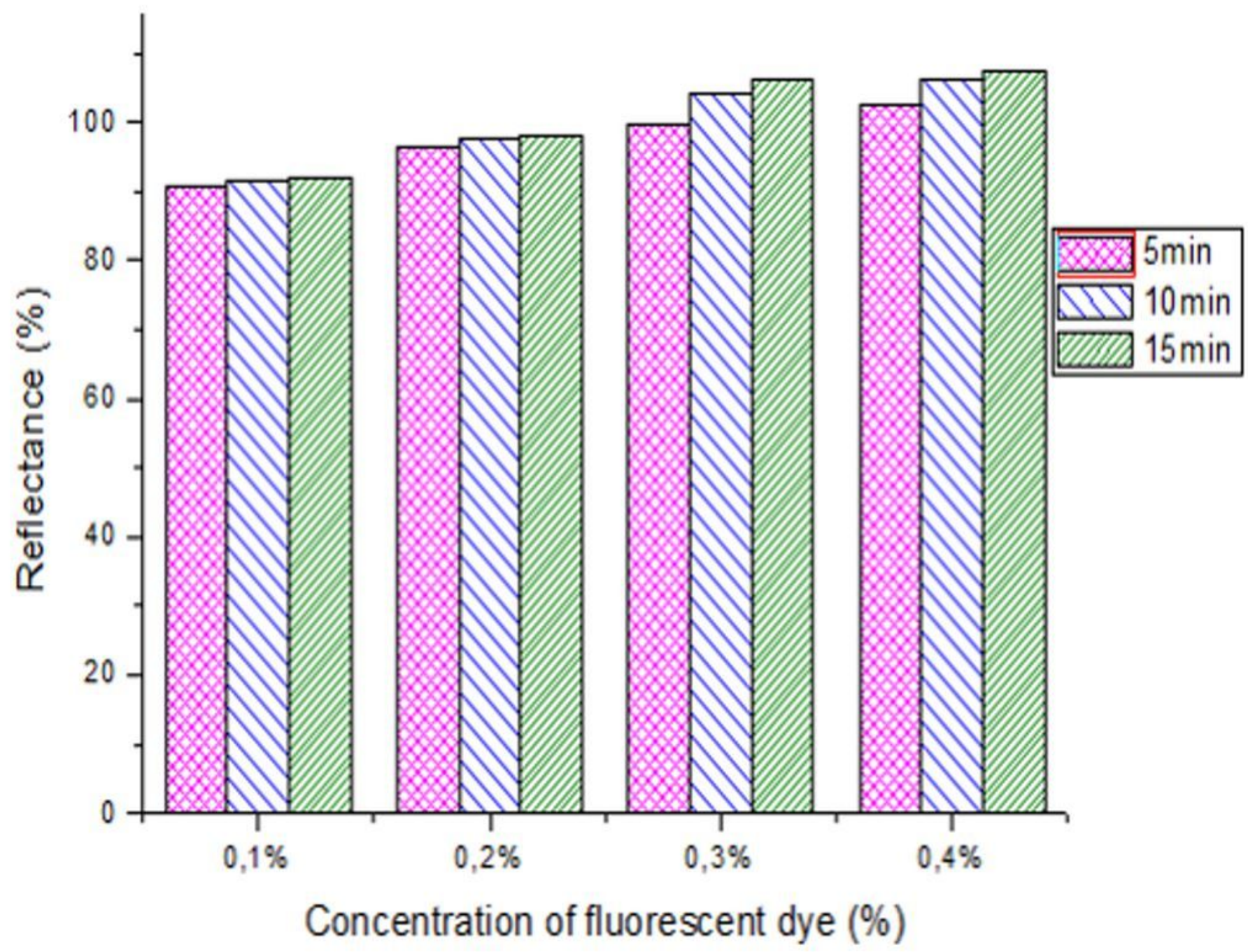

Figure 7

Effect of irradiation time on the reflectance at $560 \mathrm{~nm}$ emission wavelength 


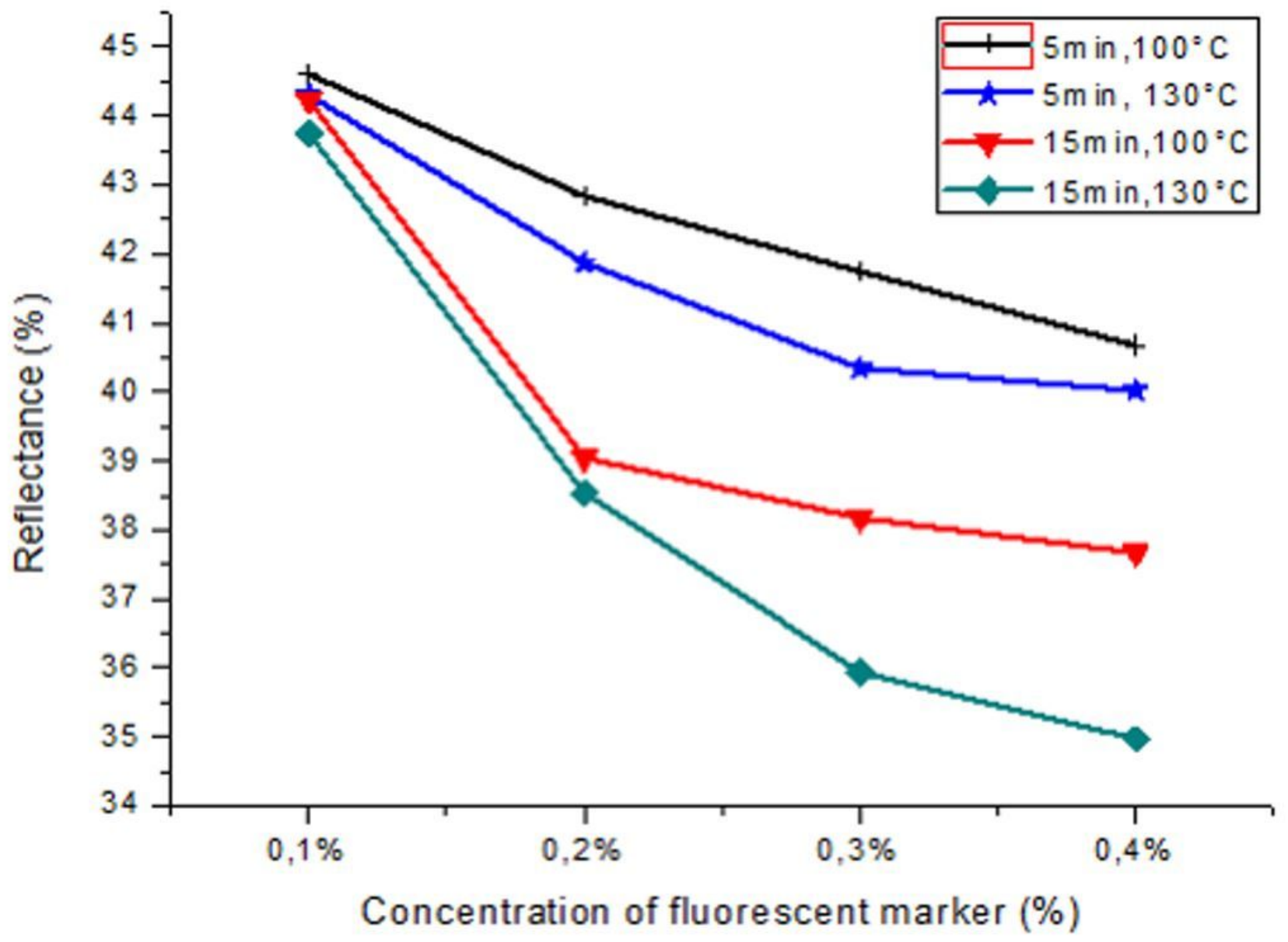

Figure 8

Effect of dye concentration on the reflectance at $560 \mathrm{~nm}$ emission wavelength 


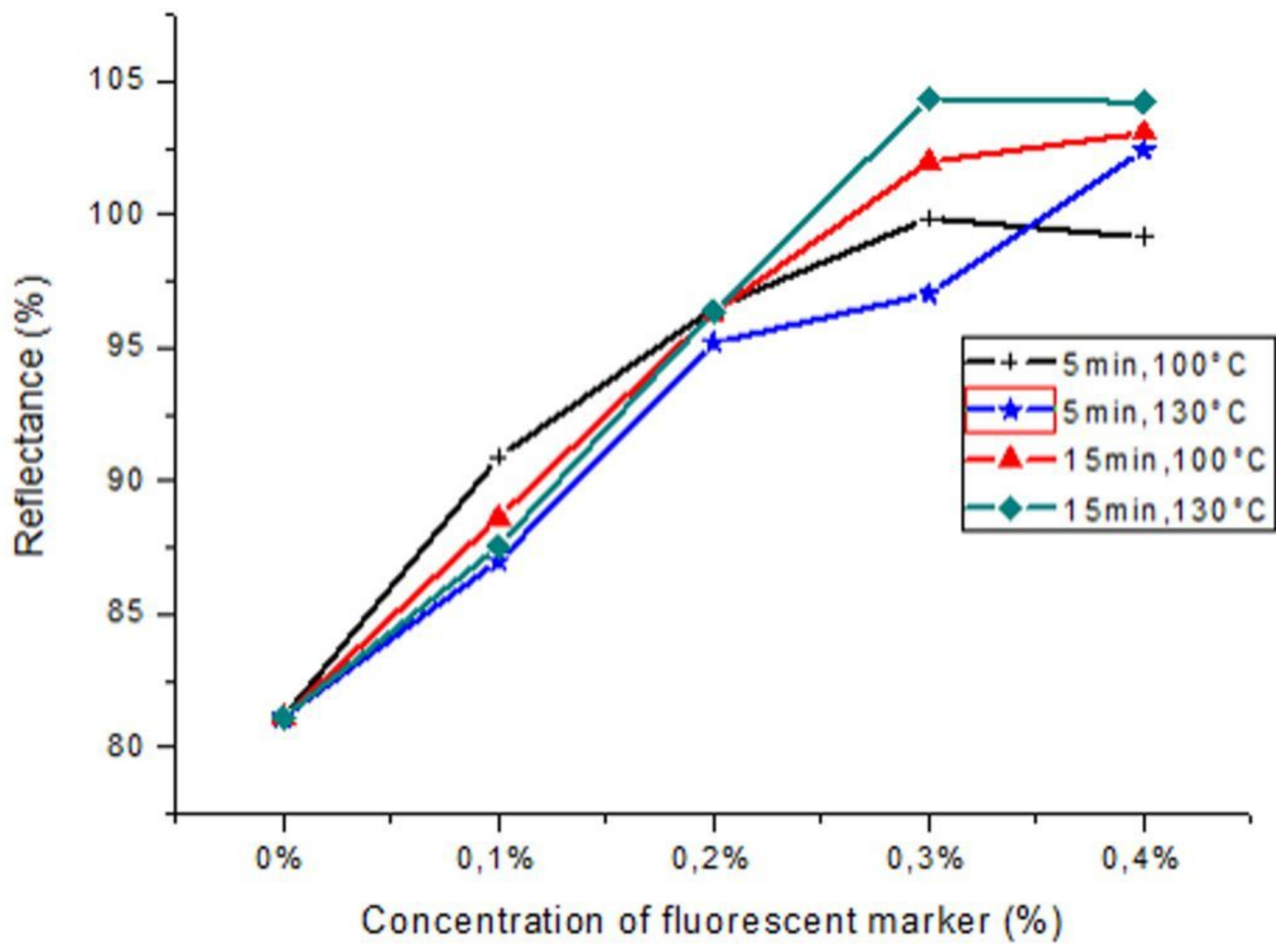

Figure 9

Effect of dye concentration on the reflectance at $560 \mathrm{~nm}$ 


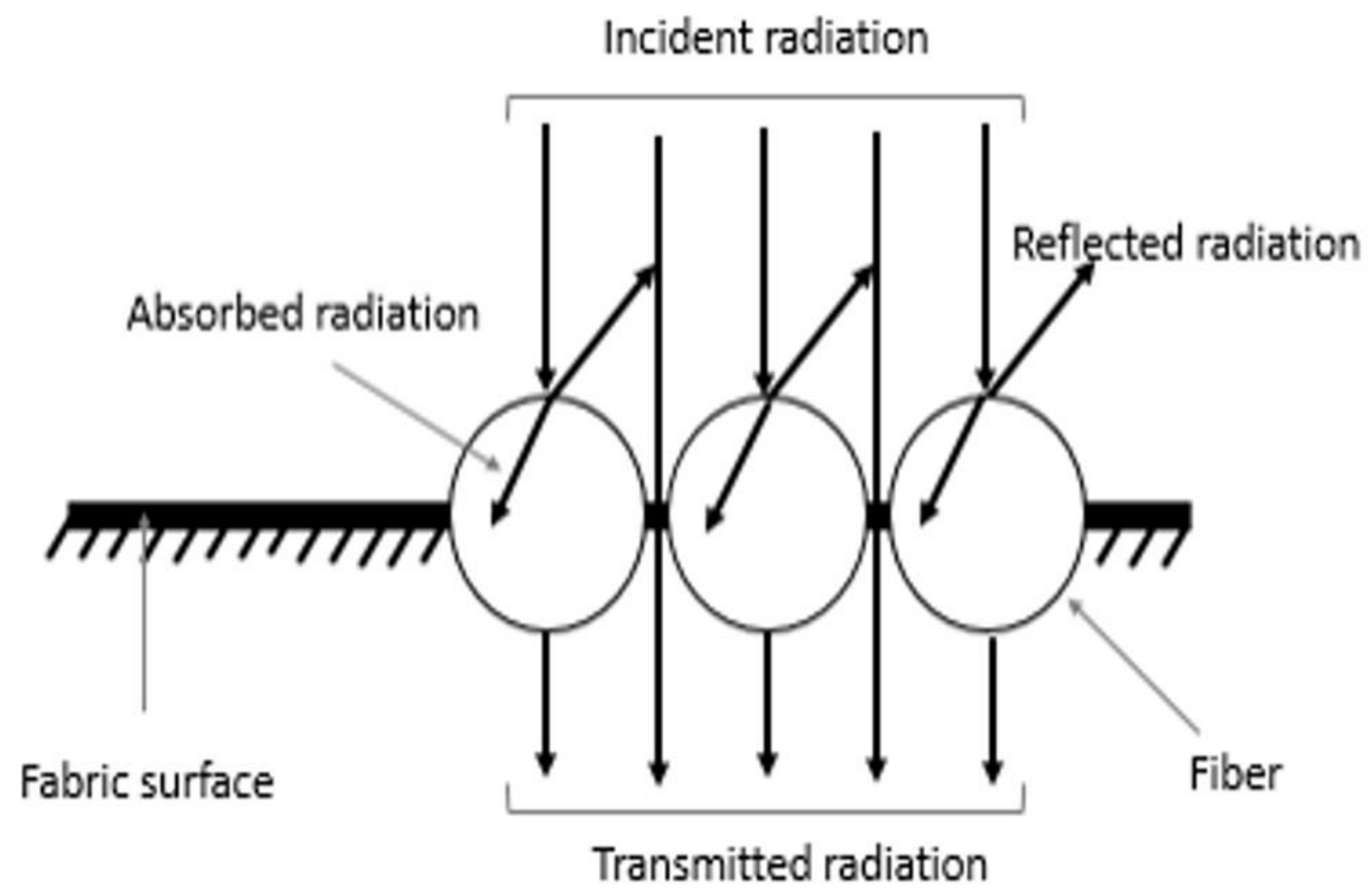

Figure 10

Radiation in contact with a textile surface 


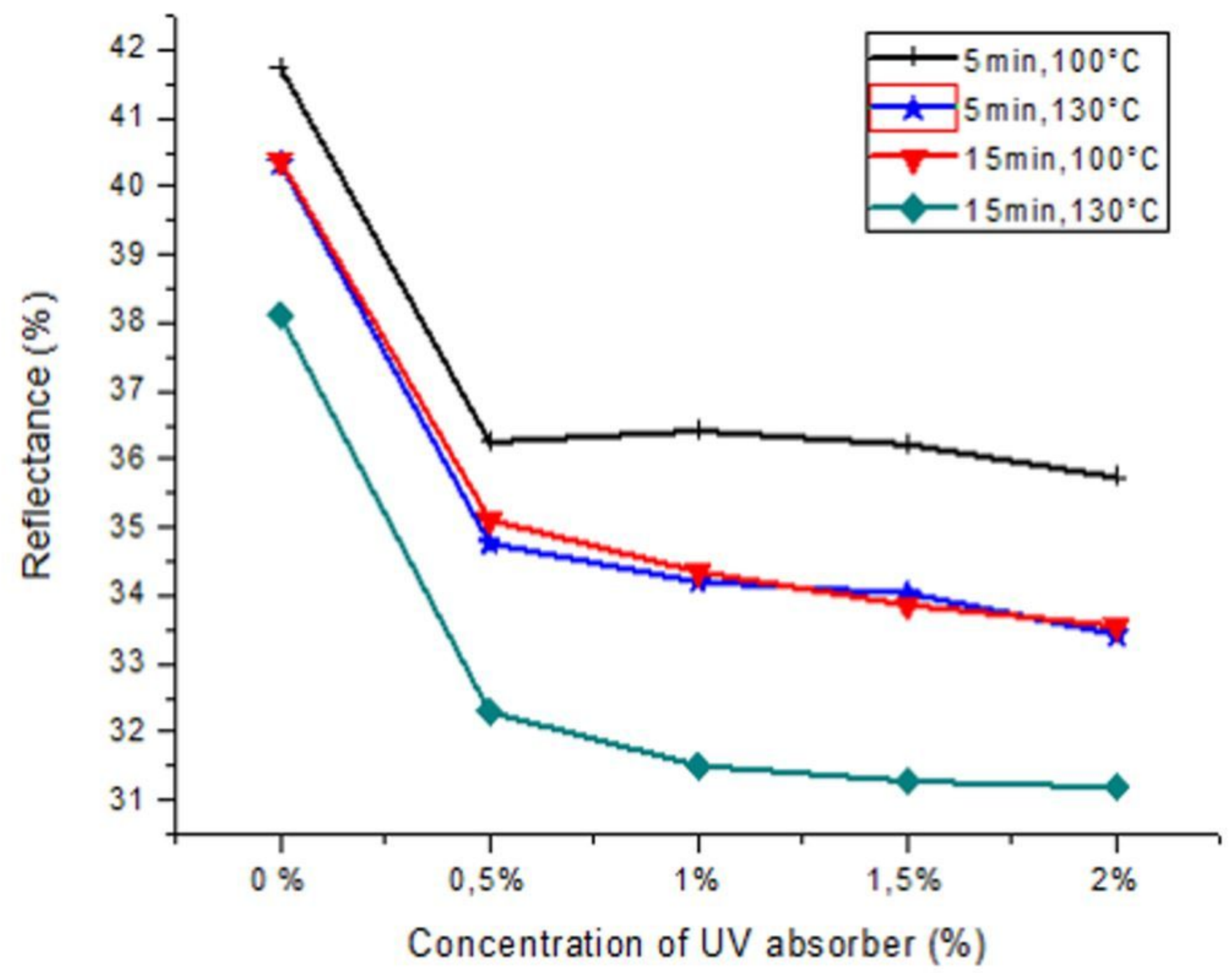

Figure 11

Effect of UV absorber concentration on the reflectance at $460 \mathrm{~nm}$ absorption wavelength 


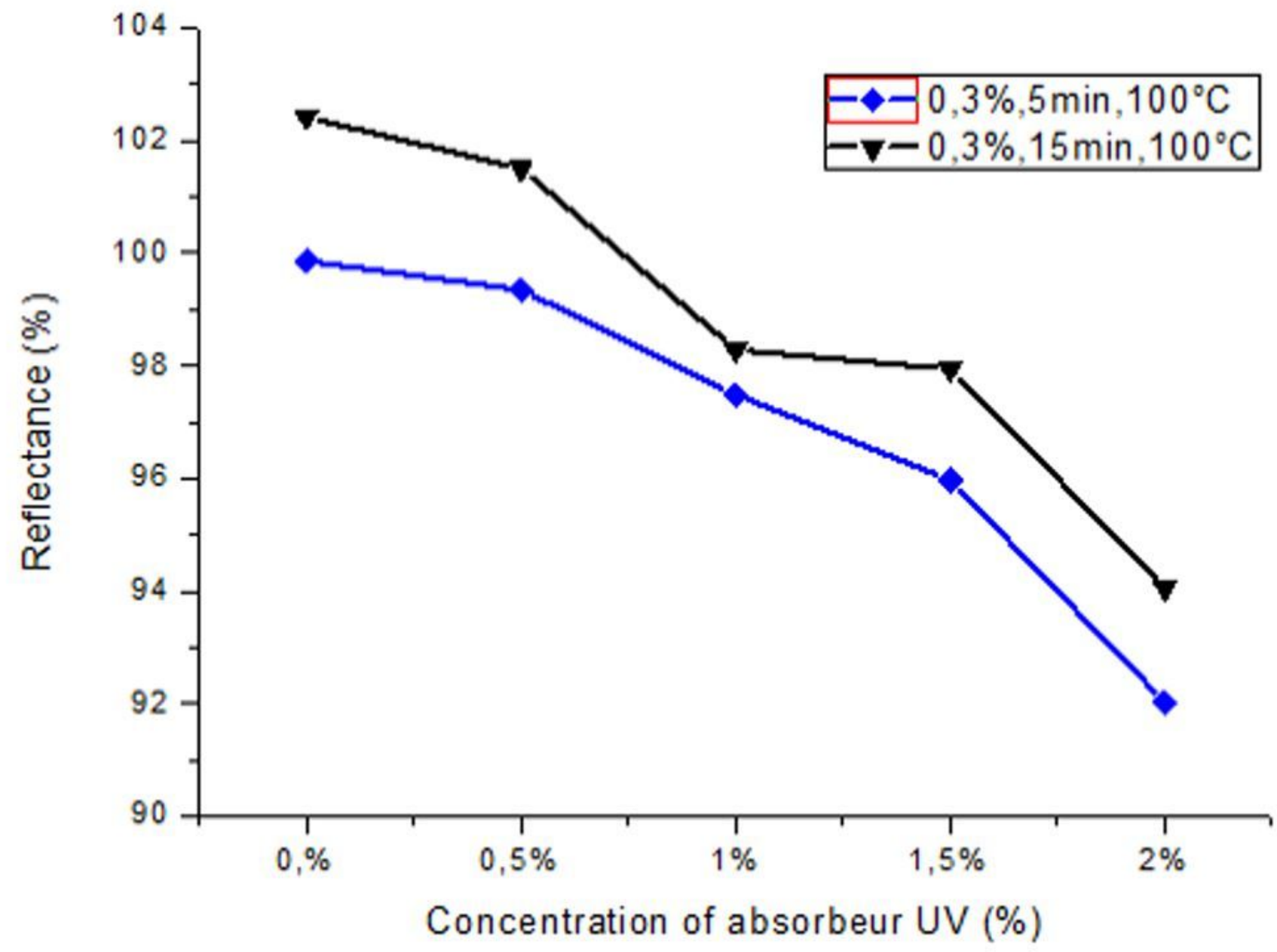

Figure 12

Effect of UV absorber concentration on the reflectance at $560 \mathrm{~nm}$ emission wavelength 
(a)

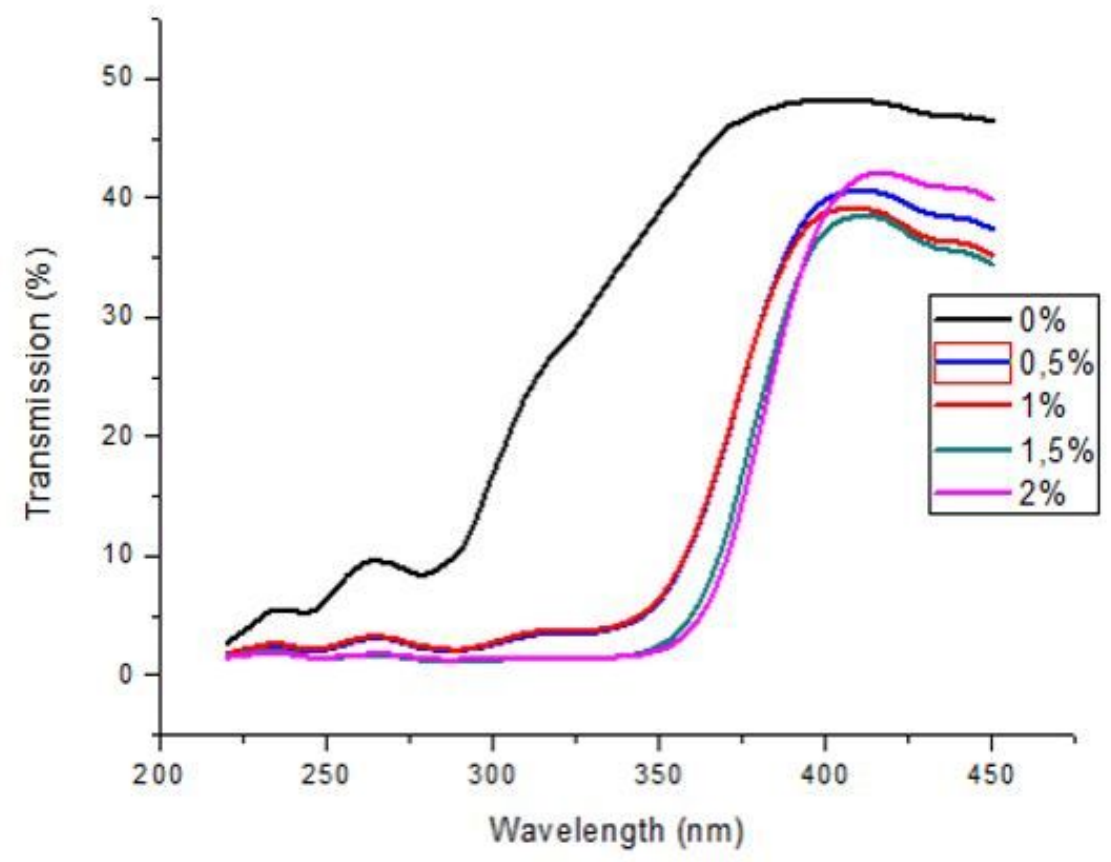

(b)

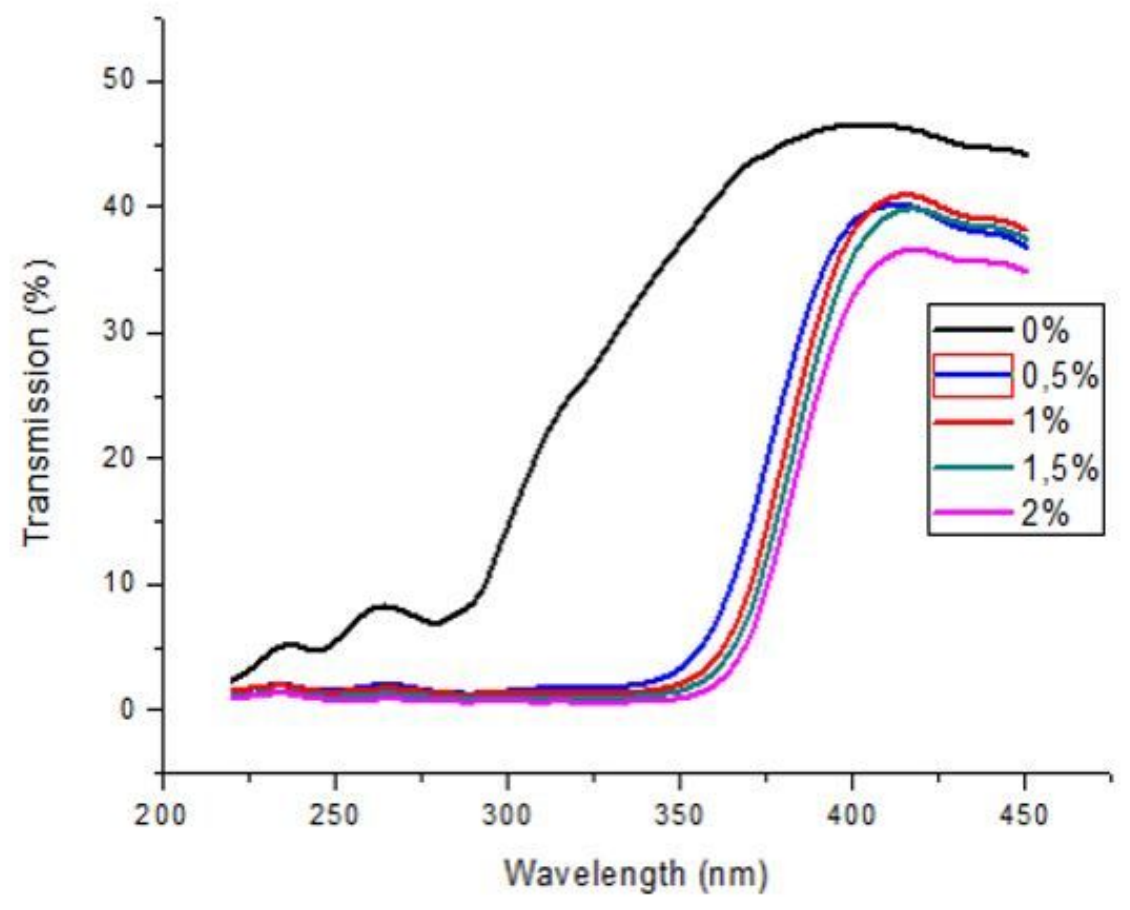

Figure 13

Effect of UV absorber concentration on the transmission of fluorescent polyester, (a) microwave irradiation time of $5 \mathrm{~min}$ and (b) microwave irradiation time of $15 \mathrm{~min}$ 


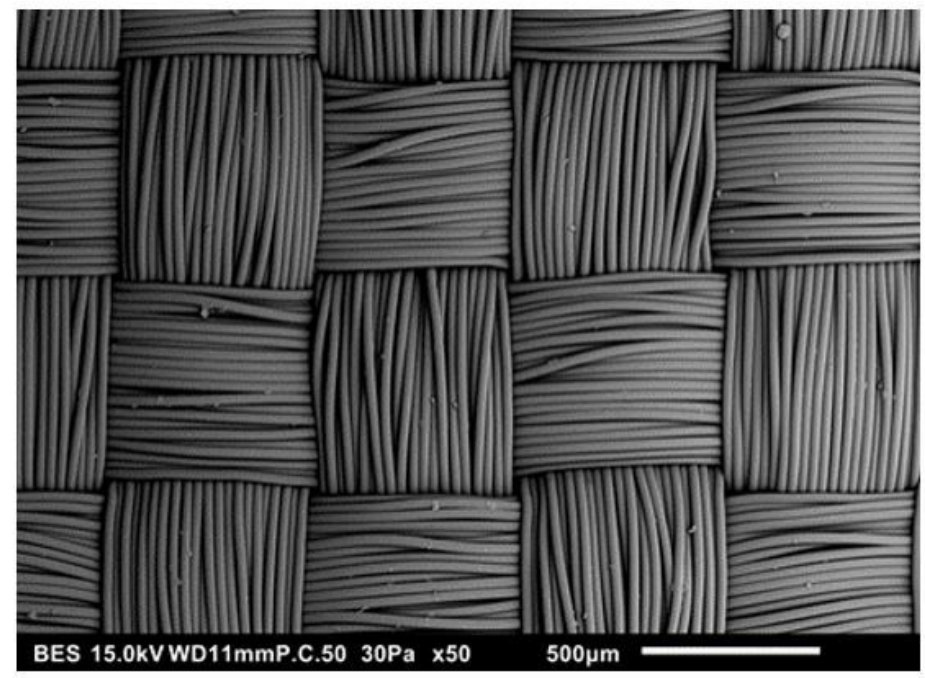

(a)

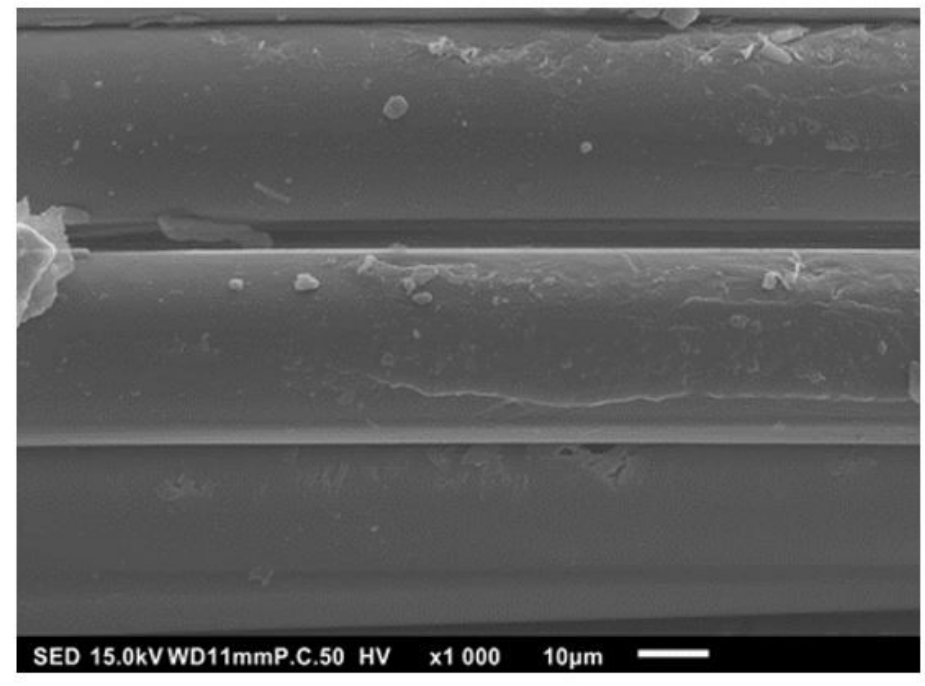

(c)

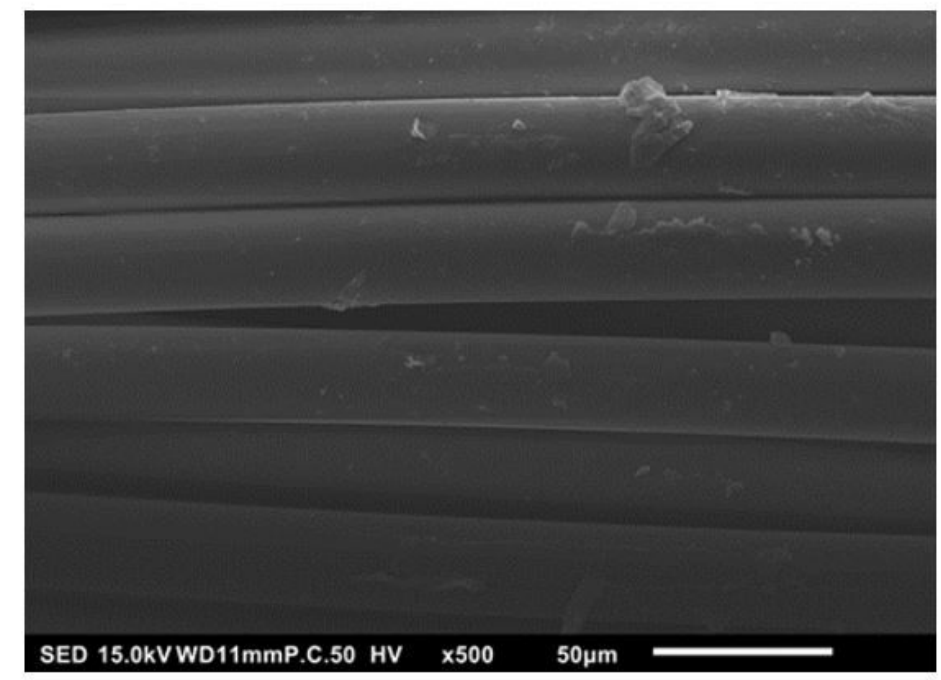

(b)

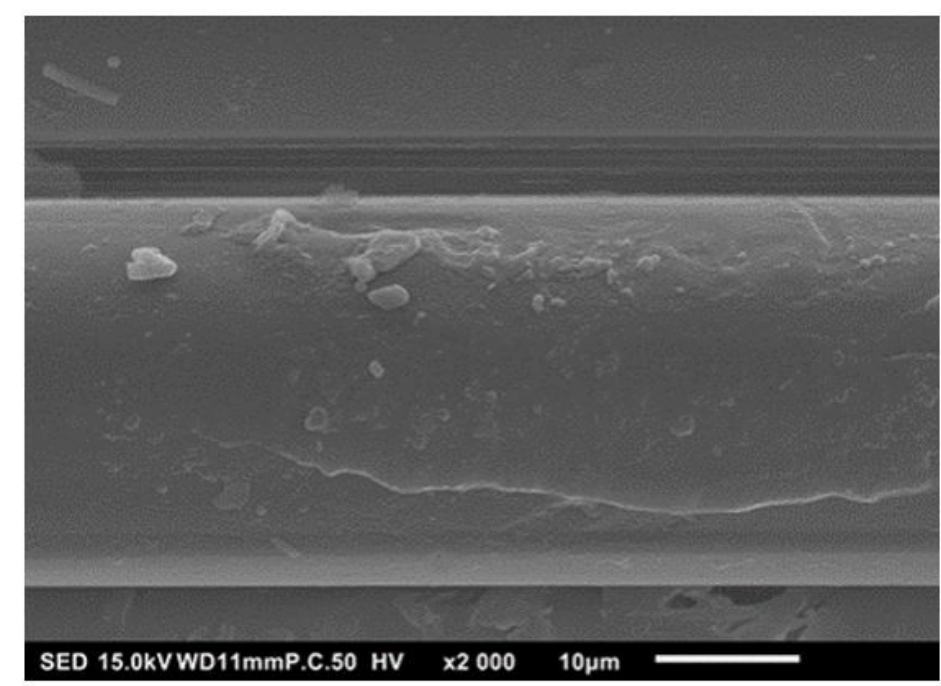

(d)

\section{Figure 14}

The SEM micrographs of polyester fabrics after dyeing with fluorescent Yellow tracer; (a) shows the SEM micrographs of polyester surface under magnification ( $\times 50)$; (b), (c) and (d) shows the SEM micrographs of fiber polyester under magnification $(\times 500),(\times 1000)$ and $(\times 2000)$ respectively 